\title{
Experimental investigation of wave-in-deck impact events on a TLP model
}

\author{
Nagi Abdussamie ${ }^{1}$, Yuriy Drobyshevski ${ }^{1}$, Roberto Ojeda ${ }^{1}$, Giles Thomas ${ }^{2}$, Walid Amin ${ }^{1}$ \\ ${ }^{1}$ National Centre for Maritime Engineering and Hydrodynamics, Australian Maritime College \\ University of Tasmania, TAS 7250, Australia \\ ${ }^{2}$ Department of Mechanical Engineering \\ University College London, UK
}

\begin{abstract}
Model tests were conducted to investigate the global response of a conventional tension leg platform (TLP) due to wave-in-deck loads associated with extreme wave events in irregular long-crested waves of a cyclonic sea state. The experimental setup was designed to allow for the simultaneous measurement of wave surface elevations, rigid body motions, tendon tensions, as well as the pressure distribution at the model's deck underside. The obtained results demonstrated the variability of all the measurements and provided insights into the effect of wave-in-deck loads on the platform behaviour, tendon tensions and slamming pressures and showed qualitative correlations between these parameters. Based on the repeated tests in several events with different wave parameters, general observations and conclusions were made with respect to the platform dynamics during the deck impact, tendon tensions, slack tendon situations, tendon ringing and local impact pressures. The results of this study could be used for calibrating computational fluid dynamics (CFD) tools.
\end{abstract}

Keywords: Extreme waves; cyclonic conditions, tension leg platforms; wave-in-deck loads; dynamic response. 


\section{Introduction}

In recent years, much effort has been made to investigate wave-in-deck impact problems in offshore platforms through experimental and numerical methods or a combination of both. Nevertheless, the current engineering knowledge required to accurately predict the magnitude and distribution of wave-in-deck loads and the resulting global response of a floating structure remains limited (Scharnke and Hennig, 2015, Lee et al., 2014, Hirdaris et al., 2014, Rudman and Cleary, 2013).

In the 2004 - 2005 year period, hurricanes Ivan, Katrina and Rita in the Gulf of Mexico destroyed 126 offshore structures and severely damaged 183 other structures (Kaiser et al., 2009). The reported damage suggests that during tropical storms or hurricanes the wave height exceeds the design height for many existing offshore structures. Most recently, in December 2015, the living quarters of 50 workers of an offshore drilling rig in the North Sea were damaged when an extreme wave hit the accommodation block leaving one person dead and two more injured (REUTERS, 2016). It has been found that these deck impact events occur more frequently than have been predicted using theoretical methods (Naess and Gaidai, 2011).

The majority of cited research conducted on wave impact on offshore decks has focused on investigating simplified deck boxes or flat plates. However, under deck structures, such as columns and pontoons, can affect the force magnitude and its distribution on the upper deck structure. Owing to the hydrodynamic interaction between the columns and pontoons of a multi-column platform such as tension leg platform (conventional TLP), the diffraction and radiation effects can cause the wave elevation to increase and locally impact the lower deck (Niedzwecki and Huston, 1992, Scharnke and Hennig, 2015, Abdussamie et al., 2016a). Niedzwecki and 
Huston (1992) found that column spacing plays a major role in the wave upwelling underneath the deck and thereby it may affect the vertical wave-in-deck force. Abdussamie et al found that the deck-column intersection areas of a fixed TLP model under the action of long-crested irregular waves experienced larger wave-indeck slamming pressures than the middle areas of the deck underside. Scharnke and Hennig (2015) investigated the effect of substructures on the wave-in-deck load magnitude by attaching a box-type deck structure to a square column. It was found that the column presence had a significant effect on the magnitude of global vertical forces and local pressures; the load magnitudes were significantly increased. With the column present, the upward peak of the vertical wave-in-deck force increased to more than double the maximum load measured without the column.

Wave-in-deck slam events may produce major global and local loads on floating offshore structures. Global loads can generate large forces in the tendons and risers and adversely affect the floating structure's motions, whilst local loads can cause structural damage to the deck and equipment impairing the safety of operation and life on-board (DNV, 2009). A significant part of the tendon tension experienced by a TLP during storm conditions can be associated with the ringing response, which is a narrow band process due to low damping in heave motion (Johannessen et al., 2006, Hennig et al., 2011). Thus, there is a need to investigate the dynamic behaviour of a TLP installation due to wave-in-deck slam events.

Among the known theoretical approaches, the momentum method developed by Kaplan (1992, Kaplan et al., 1995), has been used extensively to estimate the wave impact and slamming loads on fixed offshore platforms. For instance, the method has been applied for the analysis of wave impact on decks of Gravity Based Structures (GBS) (Baarholm and Stansberg, 2005) as well as other fixed offshore 
platforms (Baarholm, 2009, Baarholm and Faltinsen, 2004). The use of the momentum method is also recommended by classification societies for analysing wave impact forces on decks of floating platforms. Baarholm et al. (2001) investigated theoretically an extreme wave impact on the deck of a semisubmersible platform due to regular waves. The authors used a Wagner based approach to account for the platform motions and Stokes second order wave theory to describe the incident waves. The panel code WAMIT was used to obtain the transfer functions for the linear induced motions. The authors concluded that the deck impact caused a significant suction force which led to a large downward heave motion. With application to fixed structures, attempts have been made to predict the slam pressure and its distribution through the deck area using the linear wave theory. Wang (1970) developed a theoretical formula for the impact pressure on a flat plate of negligible thickness, which demonstrated good qualitative agreement with the pressure measured in model tests. The limitations of the momentum and similar methods are related to its use of wave kinematics of a non-disturbed wave field or otherwise relying on the potential flow theory for an incompressible fluid; this implies that no consideration is given to the effect of trapped air or viscous effects.

Methods based on the computational fluid dynamics (CFD) have therefore received an increasing amount of attention in recent years. Commonly used commercial codes such as STAR-CCM+ and ANSYS FLUENT are available for modelling and solving wave-in-deck impact problems using the volume of fluid (VOF) method to capture free-surface hydrodynamic flows (CD-Adapco, 2012, Fluent, 2009). Nevertheless, CFD-based techniques have still limited acceptance for practical use for modelling a moored floating body subjected to extreme waves in an irregular sea state. 
Model tests have previously been carried out to estimate wave-in-deck forces on different types of offshore structures. Model tests remain arguably the best approach for estimating wave-in-deck loads (Scharnke et al., 2014). The vast majority of published work has been focused on measuring global wave-in-deck impact forces on simplified deck boxes or flat plates fixed in space and subjected to regular waves (Bhat, 1994) and random waves (Sun et al., 2011). On the other hand, investigations of typical multi-column floaters are scarce. Furthermore, most investigations conducted on such structures are subjected to project confidentiality requirements and are therefore not available in the public domain. Experimental examination of wave-in-deck impacts on floating offshore structures seems to have started in the mid-2000's. Among few studies, Johannessen et al. (2006) and Hennig et al. (2011) investigated the dynamic air gap, wave loads and response of TLP models under extreme wave conditions. Both investigations reported that a wave-in-deck event can lead to an additional extreme response mechanism, and a step change in the extreme loading was noticeable due to such events. At the same time, the distribution of the wave-in-deck slam pressure around the forward and aft columns of a multi-column floating platform and its correlation with the global loads, including the tendon tensions, has not been systematically studied. Reports of accurate measurements and prediction of global loads and dynamic response of floating offshore structures due to wave-in-deck impact events are extremely limited. As the CFD-based techniques for the prediction the dynamic response of a moored floating body continue to be developed (for instance, an overset mesh technique (Chen et al., 2008), experimental wave-in-deck data are necessary to validate the CFD simulations and to provide information that can be used in the design of such platforms. 
The objective of the present study is to investigate the global response of a conventional TLP due to wave-in-deck impacts by performing model tests under several different extreme wave events and their repeated realisations. The study is focused on providing both qualitative and detailed quantitative insights into the wavein-deck impacts, rigid body motions, tendon tensions and deck slam pressures and their correlation. The response of a TLP model was examined in several irregular wave events with different wave kinematics, which were taken from a typical 10,000year return period cyclonic sea state at the Australian North West Shelf. By conducting tests for several wave events with repeated realisations, the study aims at estimating the variability of the measured platform responses and providing conclusions which may be broadly applicable to many floating structures of this type. The present study also aims at providing detailed results which can be used for calibrating global performance analysis software and CFD simulations. To enable the model test results to be used for the comparison with future numerical simulations, detailed information is presented on the model and the results, including the wave elevations measured at different wave probes. More detailed information, such as the time series of the measured wave elevations, is also available. One approach that can be used to numerically simulate the results of this experimental investigation is the focused wave technique, also known as the NewWave theory, developed by Tromans et al. (1991). Although most reported investigations have used the focused wave technique to investigate the response of fixed structures, e.g., Westphalen (2011) and Deng et al (2016), Ransley (2015) has demonstrated that a similar approach can be applied to investigate the dynamic response of a floating moored structure. Such technique requires the time history of wave elevation at a point which is provided in this paper and in the Research Gate page of the first author 
(Abdussamie, 2017). CFD users should note while the measured wave time history can be reconstructed by using a superposition of linear wave components through direct Fourier transform, the linear wave components obtained will not produce the correct wave at the model location due to nonlinear wave interactions. An iterative technique is therefore required to adjust the amplitude and phase of each wave component to reconstruct the target wave time history at the desired location. For more details about this technique, please refer to Wu et al. (2014).

The material is set out as follows. Section 2 describes the TLP model, instrumentations and model testing procedure. Section 3 describes the wave conditions selected for this study, which are representative of the 10,000-year return period cyclonic sea state in the Australian North West Shelf. Section 4 presents the experimental setup and the results of free decay tests in different degrees of freedom. Section 5 introduces uncertainty analyses of experimental data of wave, forces and slam pressures. Section 6 discusses the obtained results of the model's dynamic response, tendon tensions and the slam pressure distribution. Supplementary time histories of different wave realisations and the corresponding surge motions and loads are given in the Appendix.

\section{Model and Instrumentation}

\subsection{Model Testing Facility}

The model tests were conducted at the Australian Maritime College towing tank, which is $100 \mathrm{~m}$ long and $3.55 \mathrm{~m}$ wide and can be operated at a maximum water depth of $1.5 \mathrm{~m}$. The towing tank is equipped with a wavemaker for generating regular and irregular waves of different spectral properties, within the range of wave heights of $0.05-0.3 \mathrm{~m}$ and wave periods $0.6-3.5 \mathrm{~s}$. To examine the platform response and 
its dependency on the wave properties, neither wind nor current conditions are modelled.

\subsection{TLP model}

The 1:125 scaled model based on the SNORRE-A tension leg platform (Almeland et al., 1991) has been tested, with the platform deck modelled as a box-shaped structure. The main particulars of the platform at full scale and model scale are given in Table 1 and Figure 1. Due to the limitation of the maximum water depth in the towing tank $(1.5 \mathrm{~m})$, the scaled water depth does not represent the actual water depth at SNORRE-A location. Whilst the axial stiffness of the TLP tendons was modelled to represent their actual full-scale length $(307.0 \mathrm{~m})$ the modelled water depth corresponded to a full-scale water depth of $187.5 \mathrm{~m}$. This approach is considered acceptable since this study aims at investigating the hydrodynamic deck loads of a generic TLP platform rather than the response of a specific TLP installed at a specific water depth.

As the objective of this investigation is to get an insight in typical wave-in-deck events, the height of the deck of the scaled TLP model had to be defined carefully. In order to achieve a sufficiently large number of impact events in an irregular sea state waves (DNV, 2010), the static deck clearance of the platform is set to $15.0 \mathrm{~m}$ (120 $\mathrm{mm}$ in model scale), which is reduced by $12.0 \mathrm{~m}$ (92 $\mathrm{mm}$ in model scale) compared with the prototype. This modification is a compromise adopted to ensure a sufficient number of wave impact events could be observed and analysed during the model tests, even though the frequency of such events will be higher than that for the actual full-scale platform in the same sea state. The differences in deck clearance between the SNORRE-A platform and the model used in this investigation 
are illustrated in Figure 2. The frequency of expected wave impacts is further discussed in Section 3.

Table 1: Key particulars for the SNORRE-A TLP at full and model scales.

\begin{tabular}{llll}
\hline \hline Parameter & Full scale & $\begin{array}{l}\text { Model scale } \\
(1: 125)\end{array}$ & Tested model scale \\
\hline Column diameter, $D$ & $25.00 \mathrm{~m}$ & $200 \mathrm{~mm}$ & $200 \mathrm{~mm}$ \\
Pontoon size, $h \times w$ & $11.50 \times 11.50 \mathrm{~m}$ & $92 \times 92 \mathrm{~mm}$ & $92 \times 92 \mathrm{~mm}$ \\
Column spacing, $s$ & $76.00 \mathrm{~m}$ & $608 \mathrm{~mm}$ & $608 \mathrm{~mm}$ \\
Column height & $63.00 \mathrm{~m}$ & $504 \mathrm{~mm}$ & $505 \mathrm{~mm}$ \\
Deck size, $L \times B \times h_{d}$ & $124.50 \times 92.00 \times$ & $996 \times 736 \times$ & $608 \times 608 \times 210 \mathrm{~mm}$ \\
Deck clearance, ao & $15.00 \mathrm{~m}$ & $120 \mathrm{~mm}$ & $120 \mathrm{~mm}$ \\
Platform's draft, $d$ & $27.00 \mathrm{~m}$ & $216 \mathrm{~mm}$ & $305 \mathrm{~mm}$ \\
Displacement, $\Delta$ & $38.125 \mathrm{~m}$ & $305 \mathrm{~mm}$ & $52.15 \mathrm{~kg}$ \\
Total mass, $M$ & $101840 \mathrm{t}$ & $52.15 \mathrm{~kg}$ & $39.75 \mathrm{~kg}$ \\
Initial pretension per leg, $T_{o}$ & $77640 \mathrm{t}$ & $39.75 \mathrm{~kg}$ & $3.10 \mathrm{~kg}$ \\
Number of tendon per leg, $n$ & $6055 \mathrm{t}$ & $3.10 \mathrm{~kg}$ & 1 \\
Total tendon length at zero offset, & 4 & 4 & $1195 \mathrm{~mm}$ \\
Axial stiffness per leg, $n E A / L_{o}$ & $2.42 \times 10^{8} \mathrm{~N} / \mathrm{m}$ & $15.49 \mathrm{~N} / \mathrm{mm}$ & $15.80 \mathrm{~N} / \mathrm{mm}$ \\
Riser tension & $3320 \mathrm{t}$ & $1.70 \mathrm{~kg}$ & $1.70 \mathrm{~kg}$ \\
Centre of gravity, $C_{g}(x, y, z)$ & $\mathrm{n} / \mathrm{a}$ & $\mathrm{n} / \mathrm{a}$ & $(0.0,0.0,5.0) \mathrm{mm}$ \\
Mass moment of inertia $\left(I_{x x}, I_{y y}, I_{z z}\right)$ & $\mathrm{n} / \mathrm{a}$ & $\mathrm{n} / \mathrm{a}$ & $(5.23,5.23,5.63) \mathrm{kg} \cdot \mathrm{m}^{2}$ \\
Water depth & $310.00 \mathrm{~m}$ & $2480 \mathrm{~mm}$ & $1500 \mathrm{~mm}$ \\
\hline \hline
\end{tabular}

The model was divided into two modules, namely a hull module (columns and pontoons) and a topside deck module. Having these separate modules allowed testing of the deck individually and the deck and hull as a combined structure (Abdussamie et al., 2016a, Abdussamie et al., 2016b). The model was designed to be as stiff and as watertight as possible. As overtopping on columns was expected, the column tops were tightly closed. A $100 \mathrm{~mm}$ tall acrylic bulkhead was mounted on top of the aluminium sides to prevent green water ingress onto the deck space, as can be appreciated in the overall view of the TLP model presented in Figure 3. 
Inclining experiments and bifilar tests were conducted to determine the vertical centre of gravity and mass moment of inertia, as given in Table 1. The riser tension was modelled by a $1.70 \mathrm{~kg}$ lumped mass located $515 \mathrm{~mm}$ above the keel at the platform centre (see Figure 6b). The location of this concentrated mass was selected to represent the riser tension at the deck underside of SNORRE A.

(a)

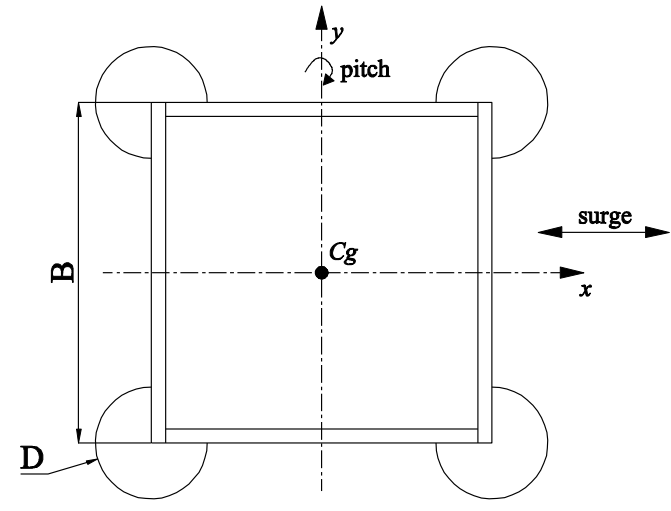

(b)

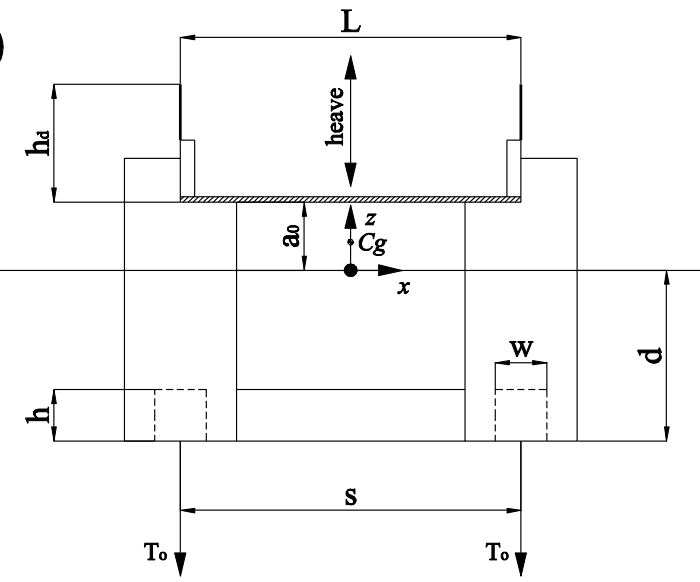

Figure 1: TLP model particulars: (a) top view; (b) profile view [not to scale]. 


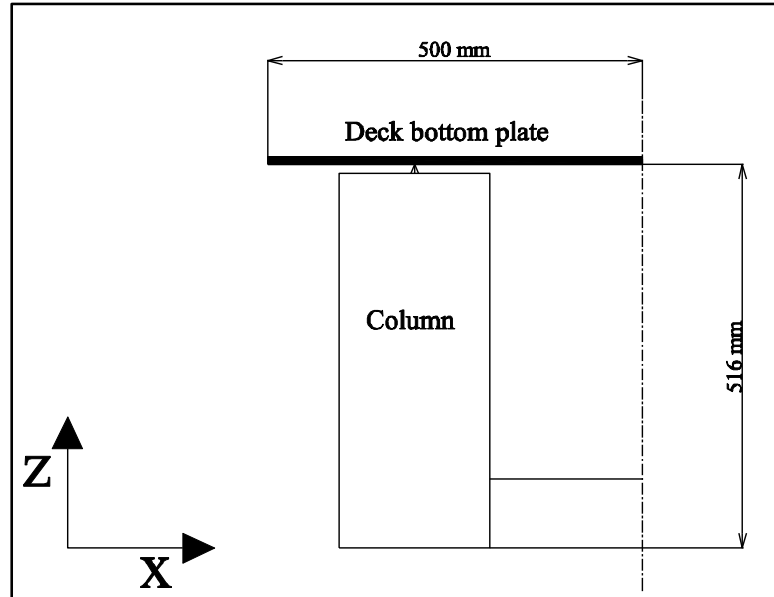

(a)

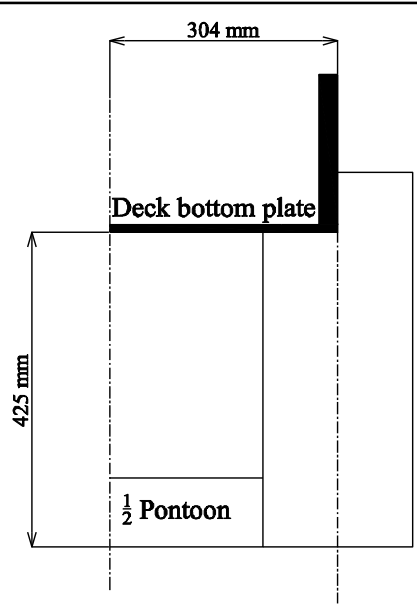

(b)

Figure 2: One-quarter of SNORRE TLP Deck and Hull showing a cross-section of the original and modified deck clearance given at model scale: (a) Original deck; (b) Modified deck.

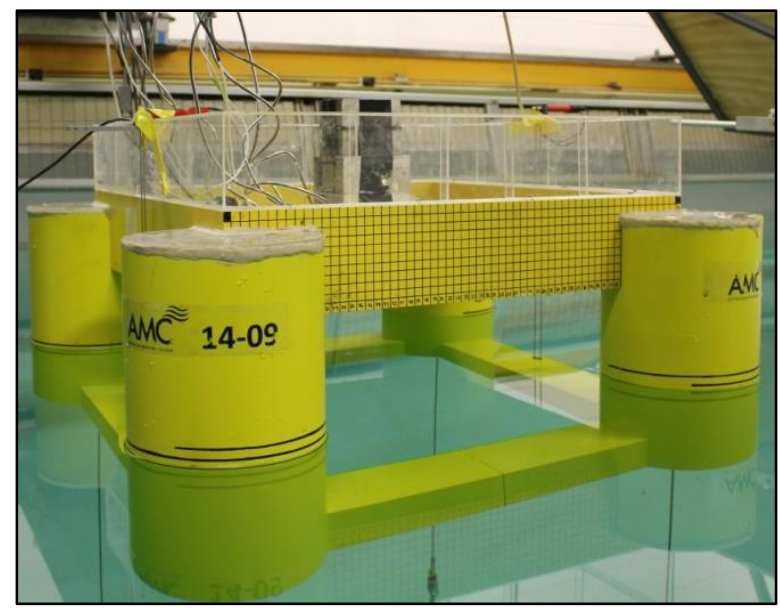

Figure 3: Photograph showing the TLP model (waves propagating from right to left).

\subsection{Tendon system}

In order to represent the mooring system of the SNORRE-A TLP, i.e., four tendons at each corner, one single tendon per corner was used at model scale with equivalent stiffness. The tendon rotation points at the TLP model end were located at the column base by installing a 3 axis hinge in each column as shown in Figure 4 . The anchor point of each tendon was fixed on the tank floor. The actual axial compliance of the four SNORRE-A TLP tendons was modelled using custom stainless steel springs representing the appropriately scaled stiffness. The light-mass 
spring with the axial stiffness of $15.80 \mathrm{~N} / \mathrm{mm}$ was installed between a $3.20 \mathrm{~mm}$ stainless steel wire rope and an anchor base (Figure 4). For Leg\#1 and Leg\#4, the spring was connected to the wire rope and a waterproof load cell. A plastic anchor block provided a strong fixture for the tendon to the tank floor. In order to adjust the initial pretension, each tendon was connected to a $1.20 \mathrm{~mm}$ wire run through the anchor base block to an adjustable turnbuckle attached to the tank side; hence providing a mechanism to remotely control tendon pretensions. The tendon pretension is $T_{0}=30.4 \mathrm{~N}$.

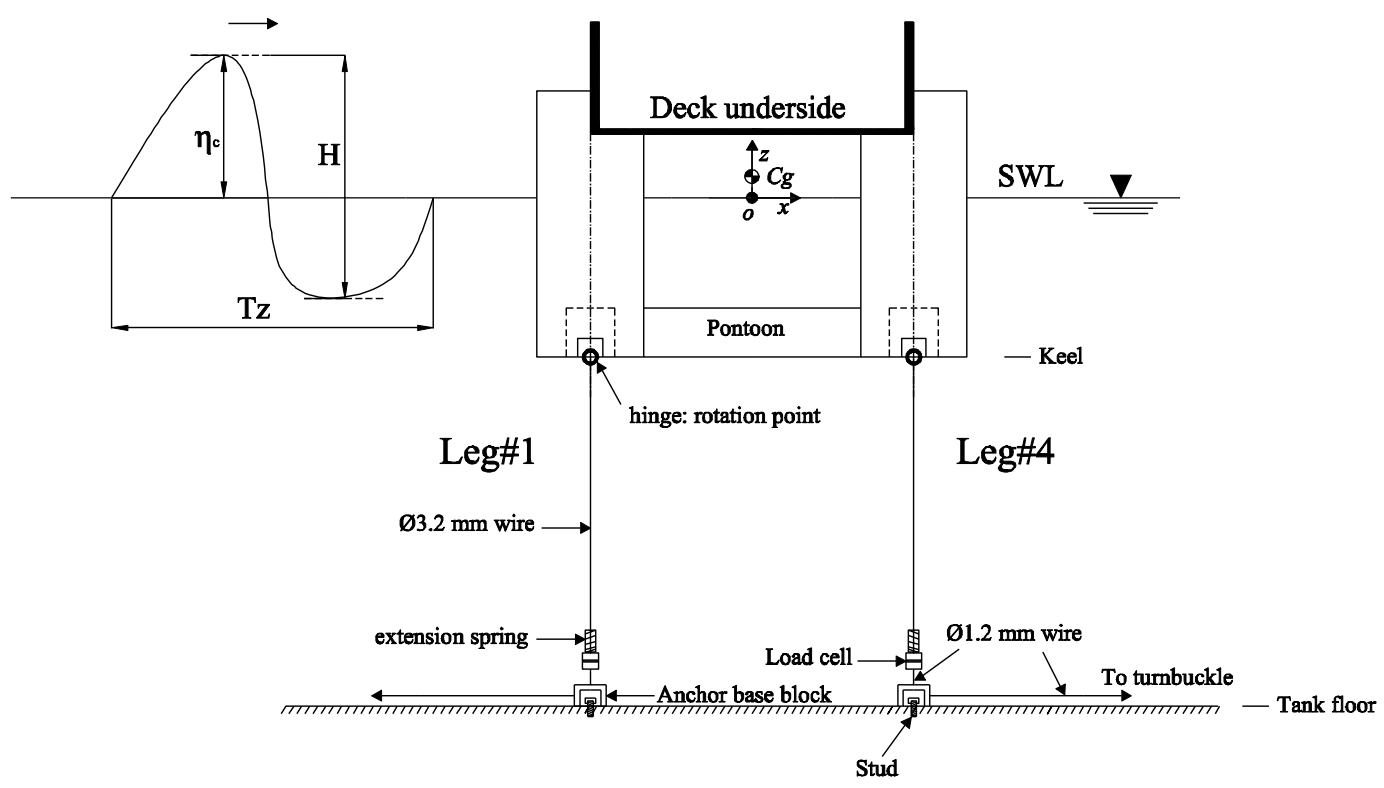

Figure 4: Profile view of the TLP model setup.

\subsection{Instrumentation}

The location of the five wave probes (WP) is presented in Table 2 (coordinate system is shown Figure 5). Wave probes WP1 - WP3 measure the wave height of the incident incoming waves travelling in the positive $x$-direction. During wave impact tests, wave probes WP4 and WP5 were attached to the leading and trailing edges of the topside deck. 
Table 2: Location of wave probes used in the model tests with respect to the model's centroid.

\begin{tabular}{|c|c|c|}
\hline Wave probe (WP) & Location $(x, y)$ without the model $(\mathrm{m})$ & Location $(x, y)$ with the model $(\mathrm{m})$ \\
\hline 1 & $(-10.000,1.280)$ & $(-10.0,1.280)$ \\
\hline 2 & $(-5.000,1.280)$ & $(-5.0,1.280)$ \\
\hline 3 & $(-1.000,0.000)$ & $(-1.0,0.000)$ \\
\hline 4 & $(-0.404,1.200)$ & $\begin{array}{c}(-0.304,0.000) \text { moving with the } \\
\text { model }\end{array}$ \\
\hline 5 & $(0.000,1.2000)$ & $\begin{array}{c}(0.304,0.000) \text { moving with the } \\
\text { model }\end{array}$ \\
\hline
\end{tabular}

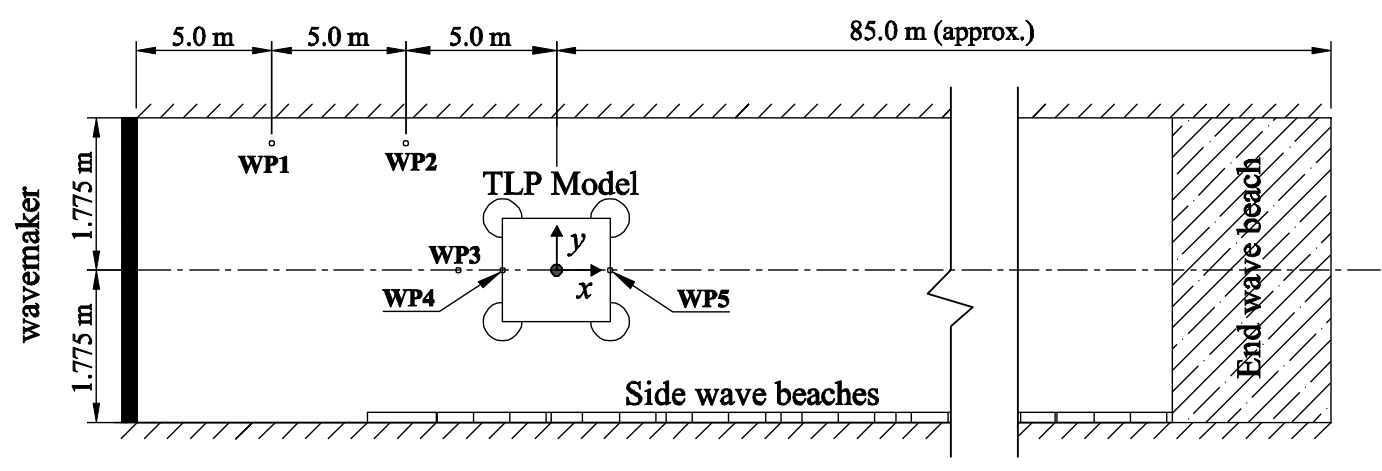

Figure 5: Plan view of the AMC towing tank showing the distribution of wave probes (WP) with the TLP model in-place [not to scale].

The model's surge motion was measured by a MagneRule magnetostrictive linear displacement transducer (MLDT), as illustrated in Figure 6 (b). In addition, an MTi-30 Xsens, six degrees of freedom motion measurement system was installed on the TLP model to measure the translational acceleration components as well as the model's pitch motion. The objective of this particular measurement system was to determine the peak pitch motion, which is associated with a wave impact event. This system was switched on simultaneously with the DAQ system, but its data set was not synchronised with the wave elevations, loads and surge data. In order to obtain the peak pitch motion caused by a wave-in-deck impact event, an approximate synchronisation was performed by comparing the time history of pitch response with the wave elevation and surge motion time histories, and with the video recording. 
This way, although it was not possible to ensure the temporal precision of the peak pitch event, the magnitude of extreme pitch angle within the cycle of a wave-in-deck impact event was identified.

(a)

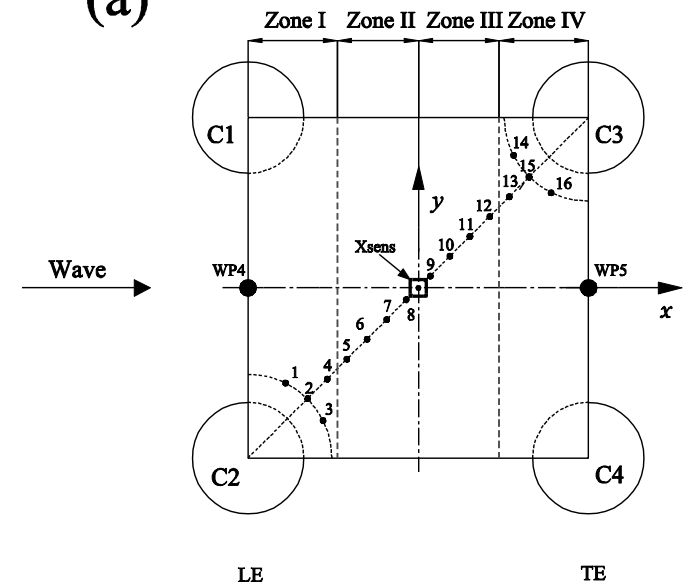

(b)

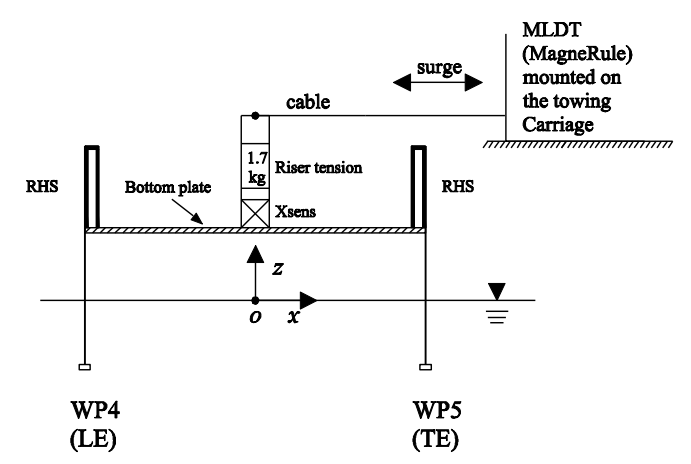

Figure 6: Instrumentation layout: (a) distribution of pressure transducers (PT) on the bottom plate; (b) profile view showing the instrumented deck structure by Xsens accelerometer and the MLDT.

Only two tendons were instrumented by two FUTEK submersible S-beam junior load cells, see Figure 4, one up-wave tendon and one down-wave tendon (denoted by Leg\#1 and Leg\#4). The underside of the topside deck structure was instrumented by sixteen piezoresistive pressure transducers (PT). The tip of each transducer (approximately $4.0 \mathrm{~mm}$ in diameter) was mounted flush with the underside of the deck. The pressure transducers were distributed over two main regions: forward (FWD) and aft (AFT) (Figure 6). The area around the forward column (C2) was instrumented by PT\#1 - PT\#4, whilst PT\#13 - PT\#16 measured wave impact pressures near the aft column, C3. The remaining pressure transducers, PT\#5 - PT\#12, were installed in the mid-span area. By referring to Figure 6 four zones along and across the deck underside were instrumented by four pressure transducers each. Table 3 shows the definition of each zone. This arrangement of local pressure transducers will enable the detailed pressure distribution to be established. 
Table 3: Definition of pressure zones at the deck underside.

\begin{tabular}{lll}
\hline \hline Zone & Definition & Pressure Transducers (PT) \\
\hline \hline I & Around forward columns & $1,2,3,4$ \\
II & Forward middle section & $5,6,7,8$ \\
III & Aft middle section & $9,10,11,12$ \\
IV & Around aft columns & $13,14,15,16$ \\
\hline \hline
\end{tabular}

High-speed cameras were used to capture both photographs and videos in various instants of several wave-in-deck impact events.

\section{Wave Conditions}

\subsection{Sea State}

The sea state used for the model testing was representative of the 10,000-year return period cyclonic storm in Australia's North West Shelf. The sea state was modelled by the JONSWAL spectrum with the significant wave height $H_{\mathrm{s}}=22.13 \mathrm{~m}$, peak period $T_{\mathrm{p}}=17.0 \mathrm{~s}\left(T_{\mathrm{p}} / \sqrt{H_{s}}=3.61\right)$, and the peak shape parameter $\mathrm{Y}=1.0$, which yields the Pierson-Moskowitz spectrum. The corresponding parameters at model scale $1: 125$ are $H s=177 \mathrm{~mm}, T_{p}=1.52 \mathrm{~s}$. The Long-crested sea state is assumed, with no effects of wind or current.

It should be noted that be the full-scale TLP studied in these model tests does not necessarily represent the best design solution in particular with respect to its static deck clearance and its exposure to a harsh sea state. In fact, the model dimensions (refer to Section 2.2) and the sea states have been selected to ensure that wave-in-deck events do occur more than once in the 10,000-year storm. Although this would be opposite to what a designer would like to achieve, such 
selection enables the wave-in-deck events to be investigated within wave trains of a reasonably short duration, less than the 3-hour design storm and featuring different wave properties.

\subsection{Wave Trains and Calibration}

Such short-time irregular wave trains were synthesised by the wavemaker using an iterative wave calibration process, which was conducted without the model in the tank. The process involved running a single random wave realisation initially for approximately 22 minutes (120 s in model scale) using a sampling frequency of $200 \mathrm{~Hz}$ for wave probes. The wave realisation would be selected for the subsequent tests if it had at least one wave crest height exceeding the static air-gap $a_{0}=120 \mathrm{~mm}$ (15.0 $\mathrm{m}$ full scale) at wave probes WP3 - WP5, which coincided with the deck edges. Nine (9) wave realisations, each approximately $450 \mathrm{~s}$ long (40 s in model scale), have been selected which contained eight (8) wave exceedance events.

Although this study does not aim at investigating a multitude of possible wavein-deck events, the selected wave trains can be considered as a sample with meaningful probabilistic interpretation. Based on the Forristall short-term distribution of wave crests (DNV, 2010), it is expected that on average 46 wave crests will exceed the static air gap $a_{0}=15.0 \mathrm{~m}$ in this sea state over a 3-hour storm duration. Therefore, nine randomly selected realisations correspond to $17.4 \%$ of all wave crests exceeding the static deck level at a given location. This selection is considered to be sufficient for making generalisations with respect to the TLP responses induced by the wav-in-deck impacts. Although broadening the range of wave events would provide more confidence in the findings, this would require model tests with longer wave trains (with the potential effect of the reflected waves) or reduce the static deck clearance (with the TLP model being less representative of a 
practical design solution). The selected combination of the model dimensions, the sea state and the wave trains represent a reasonable compromise for the purpose of this study.

\section{Experimental setup}

\subsection{Model setup}

The TLP model was set up on the tank centreline with its centroid $(x=y=0.0)$ located $15.0 \mathrm{~m}$ away from the wavemaker (Figure 5). The remaining $85.0 \mathrm{~m}$ of towing tank allowed for sufficiently long run times without interference from reflected waves (Abdussamie et al., 2014). A sampling frequency of $20 \mathrm{kHz}$ was adopted for all channels in order to capture the short-duration slamming pressures. Twenty-four channels (1 for linear displacement transducer, 2 for load cells, 16 for pressure transducers and 5 for wave probes) sampled at $20 \mathrm{kHz}$ produced a data file of approximately $220 \mathrm{MB}$ for $40 \mathrm{~s}$ of acquisition time.

\subsection{Natural periods and damping}

Decay tests were conducted for the TLP-tendon system; the logarithmic decrement method was used to determine the damping ratios. The natural periods of the TLP model were compared with the full-scale values obtained from (Johannessen et al., 2006), see Table 4. A large difference in the surge natural period was found, as expected, due to the water depth (and tendon length) not being modelled to scale. Heave and pitch natural periods agree with the full-scale data within $10 \%$ and $3.7 \%$, respectively.

Table 4: Natural periods and damping ratios of the TLP.

\begin{tabular}{lcccc}
\hline \hline Motion & Full scale [s] & Model: target [s] & Model: tested [s] & Model : Damping [-] \\
\hline Surge & 84.0 & 7.513 & 5.660 & 0.106 \\
Heave & 2.3 & 0.205 & 0.225 & 0.023 \\
Pitch & 2.4 & 0.214 & 0.222 & 0.123 \\
\hline \hline
\end{tabular}




\subsection{Test matrix}

With the TLP model being in the tank the wave parameters for each wave event (WE\#) were derived from the time history of WP3 (Figure 5). The crossing analysis was employed to estimate zero crossing period, $T_{\mathrm{z}}$, crest height, $\eta_{\mathrm{c}}$, and crest to trough height, $H$, see Figure 4 . Table 5 summarises these parameters where $\lambda$ is the wavelength estimated from the dispersion relationship. The generated wave events are non-breaking at WP3 as indicated by the wave steepness $(S=H / \lambda)$. The phase celerity, $C$, was estimated by $\lambda / T_{z}$ for each wave event. Also indicated in the table is the horizontal velocity, $u$, at the crest calculated using the Stokes second order wave theory at $z=\eta_{c}$. Although the Stokes theory may not be accurate in predicting the kinematics of extreme waves (Scharnke et al., 2014), yet, this horizontal velocity is employed as an approximate measure for comparison between the wave events.

Table 5: Wave event parameters extracted from WP3 with the TLP model in-place.

\begin{tabular}{cccccccc}
\hline \hline $\begin{array}{c}\text { Wave event } \\
\text { (WE\#) }\end{array}$ & $H(\mathrm{~mm})$ & $\eta_{\mathrm{c}}(\mathrm{mm})$ & $T_{\mathrm{z}}(\mathrm{s})$ & $\lambda(\mathrm{m})$ & $C(\mathrm{~m} / \mathrm{s})$ & $u(\mathrm{~m} / \mathrm{s})$ & $S(-)$ \\
\hline 1 & 231 & 145 & 1.48 & 3.39 & 2.29 & 0.65 & 0.068 \\
2 & 260 & 163 & 1.37 & 2.92 & 2.13 & 0.85 & 0.089 \\
3 & 238 & 171 & 1.65 & 4.16 & 2.52 & 0.60 & 0.057 \\
4 & 227 & 137 & 1.35 & 2.84 & 2.10 & 0.72 & 0.080 \\
5 & 186 & 156 & 1.76 & 4.67 & 2.65 & 0.42 & 0.040 \\
6 & 168 & 126 & 1.73 & 4.53 & 2.62 & 0.37 & 0.037 \\
7 & 191 & 144 & 1.44 & 3.22 & 2.24 & 0.55 & 0.059 \\
8 & 261 & 160 & 1.46 & 3.31 & 2.27 & 0.77 & 0.079 \\
\hline \hline
\end{tabular}

\section{Uncertainty analyses}

The uncertainty of the measured TLP responses in both time and magnitude was estimated by running several (up to five) repeats for each of 9 wave realisations and assessing the variability of the results for the waves and the responses. As an example, four runs of the wave realisation that contained two wave events WE\#2 and WE\#3, are shown in Figure 7, is described below in detail. Two deck impacts caused by wave events WE\#2 and WE\#3 can be observed at time $=5.0 \mathrm{~s}-7.0 \mathrm{~s}$ 
$(\mathrm{WE \# 2})$ and at time $=23.0 \mathrm{~s}-25.0 \mathrm{~s}(\mathrm{WE \# 3})$. Three more wave crests in this time history exceeded the static deck clearance without severely impacting the deck.

The four measured time histories of the surge motion are presented in Figure 8 and the corresponding tendon tensions are presented in Figure 9 for the up-wave (Leg\#1) and the down-wave (Leg\#4) tendons of the model. Qualitatively, all global responses show limited variability between the repeated runs. In contrast, the localised pressures measured at discrete points of the deck are found to have much higher variability in space, time, magnitude and duration. This can be seen in Figure 10, where the time series of pressure transducers PT\#8 (mid-span region) and PT\#16 (aft region of the deck) are shown for WE\#2. Although the time histories of both pressure transducers show a typical trend of the impact pressure signal, i.e., a rapid increase in magnitude followed by a slow reduction, the differences are obvious.

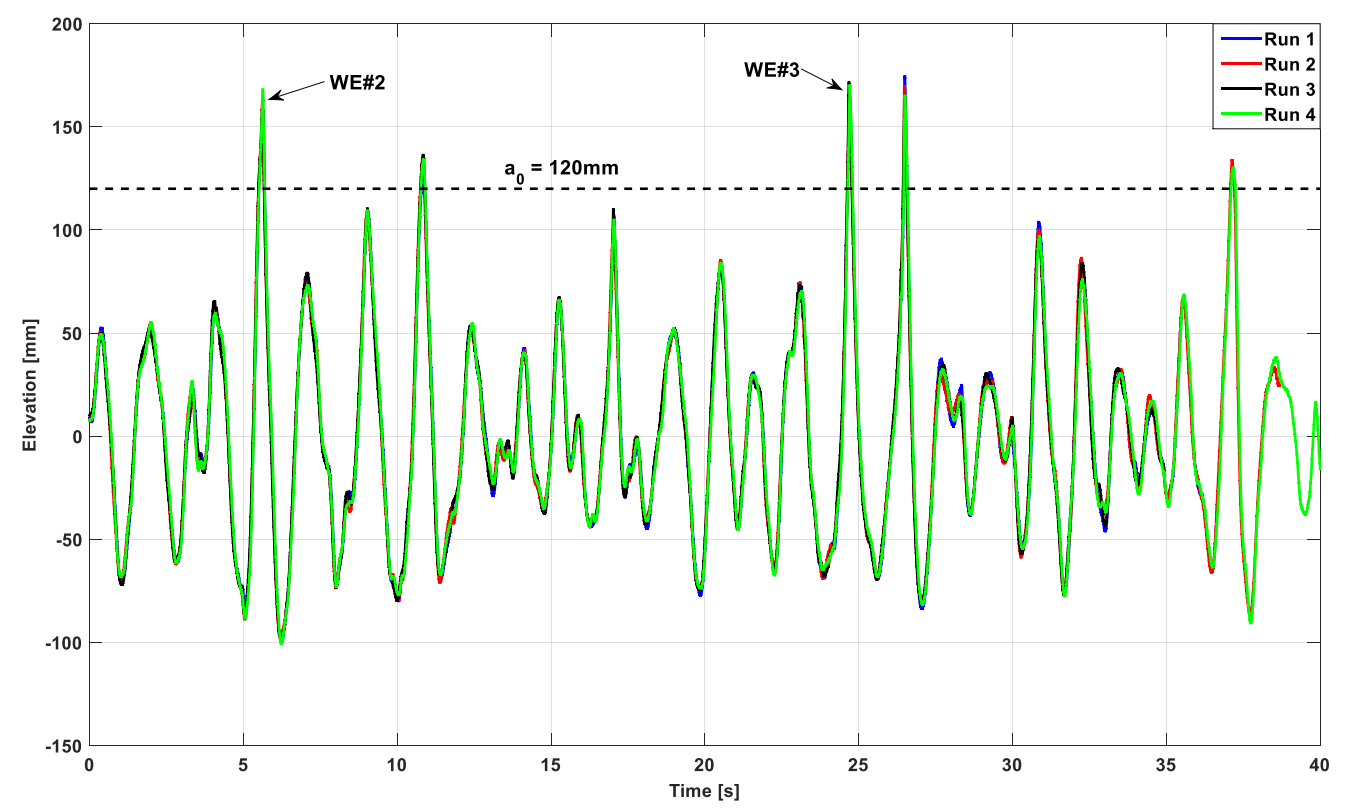

Figure 7: A short-time history of wave elevation measured by WP3 at $1.0 \mathrm{~m}$ from the model's centroid using four repeated runs. 


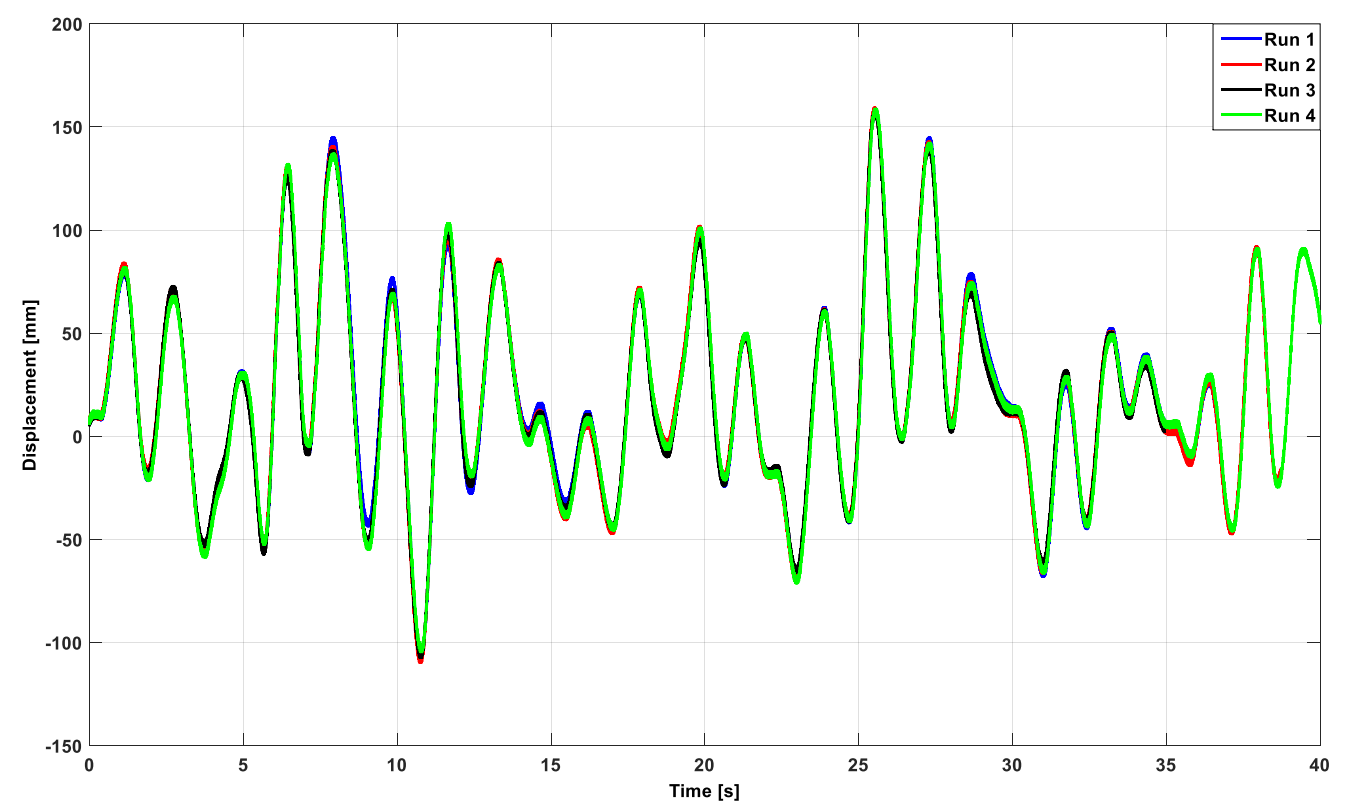

Figure 8: Time series showing surge motion measured using four repeated runs.
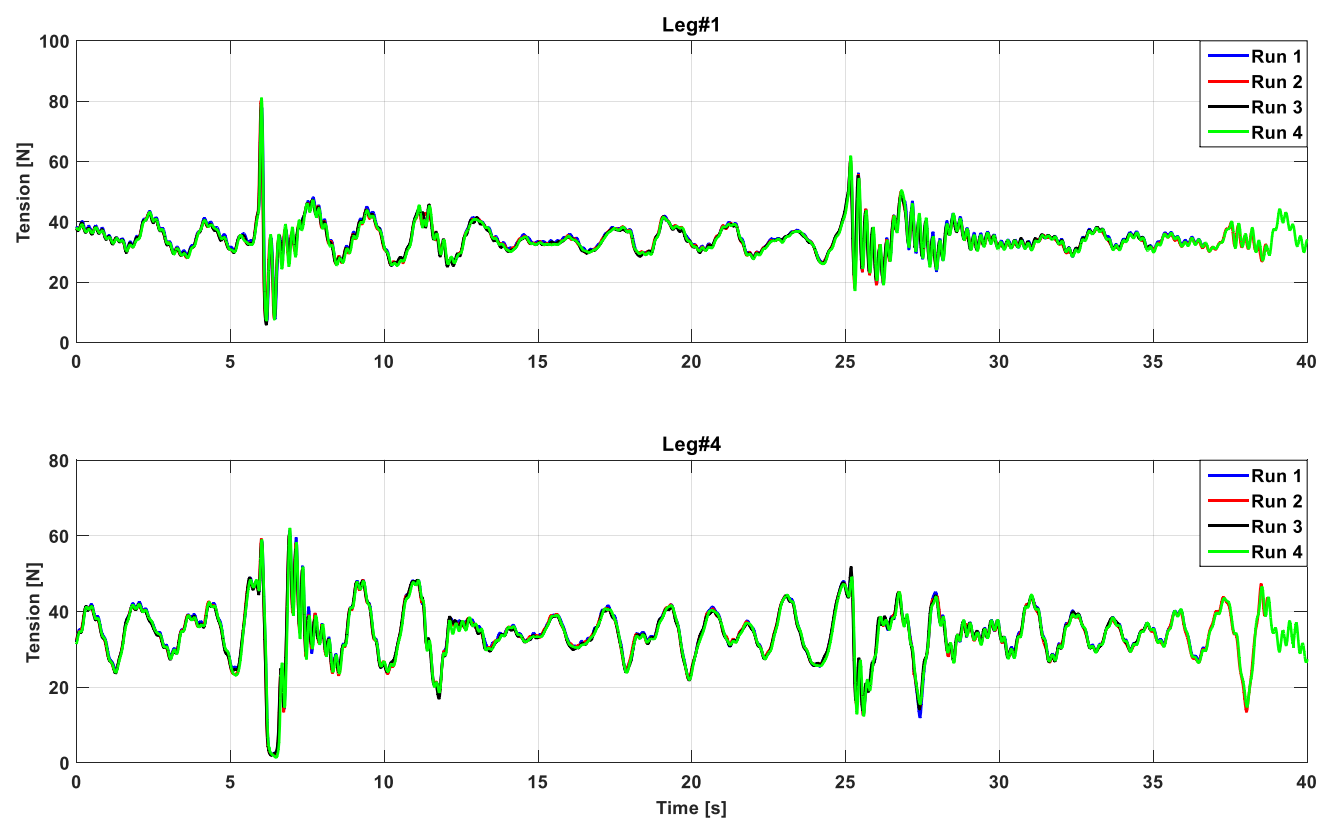

Figure 9: Time series showing tension in the platform's tendons measured using four repeated runs: up-wave tendon (top); down-wave tendon (bottom). 

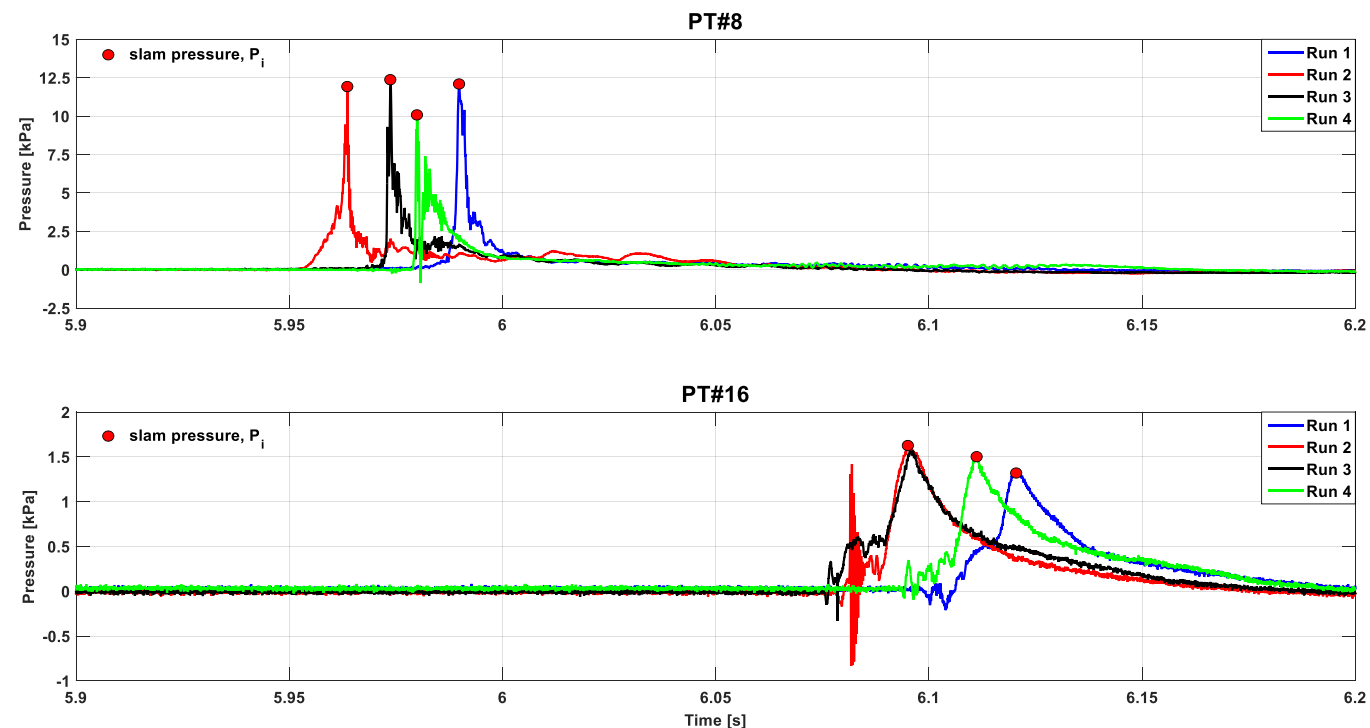

Figure 10: Time history of wave-in-deck pressures due to wave event WE\#2 [H=260 $\mathrm{mm}, T_{z}=$ 1.37 s] measured in four repeated runs: at PT\#8 (top); at PT\#16 (bottom).

The peak values of the measured wave elevations at WP3, the maximum and minimum tendon tensions (denoted by $T_{\max }$ and $T_{\min }$ ), and the slamming pressures $\left(P_{i}\right)$ at PT\#8 and PT\#16 are summarised in Table 6 - Table 8 , respectively, for the four test runs. The mean values, standard deviations and coefficients of variation (CV) are presented. The CV values for the peak wave elevations are of the order of $2.5 \%$ for the positive and $1.5 \%$ for the minimum wave elevations. The maximum CV value was found to be less than $3.0 \%$ for all wave events reported in this paper which demonstrates a good repeatability of the wavemaker. The dynamic components of the maximum and minimum tendon tensions (the initial pretension was removed: dynamic tension $=$ total tension - pretension) show similar variability for WE\#2 (within $2.8 \%$ ) and larger variability for WE\#3, with the negative tensions varying significantly more than the positive ones. 
Table 6: Uncertainty analysis of wave crests and troughs $(\mathrm{mm})$ at WP3 using four repeated runs for wave events WE\#2 and WE\#3.

\begin{tabular}{ccccc}
\hline \hline \multirow{2}{*}{ Run id } & \multicolumn{2}{c}{ WE\#2 } & \multicolumn{2}{c}{ WE\#3 } \\
\cline { 2 - 5 } & WP3(+) & WP3(-) & WP3(+) & WP3(-) \\
\hline 1 & 158 & -100 & 163 & -68 \\
2 & 162 & -97 & 169 & -67 \\
3 & 163 & -98 & 171 & -69 \\
4 & 168 & -100 & 170 & -67 \\
Mean (mm) & 162.75 & -98.75 & 168.25 & -67.75 \\
$\sigma(\mathrm{mm})$ & 4.11 & 1.50 & 3.59 & 0.96 \\
CV $(\%)$ & 2.53 & 1.52 & 2.14 & 1.41 \\
\hline \hline
\end{tabular}

Table 7: Peak values of the dynamic tension (N) measured in the up-wave tendon (Leg\#1) and down-wave tendon (Leg\#4) using four repeated runs for wave events WE\#2 and WE\#3.

\begin{tabular}{lllllllllll|}
\hline \hline \multicolumn{2}{l}{ WE\#2 } & {$[H=260$} & $\left.\mathrm{mm}, T_{\mathrm{z}}=1.37 \mathrm{~s}\right]$ \\
\hline Leg\# & Tension & Run 1 & Run 2 & Run 3 & Run 4 & Mean & $\sigma$ & $\mathrm{CV}(\%)$ & $\alpha(-)$ \\
& $T_{\max }$ & 47.5 & 49.8 & 49.2 & 50.8 & 49.3 & 1.38 & 2.81 & 1.11 \\
& $T_{\min }$ & -23.8 & -23.3 & -24.6 & -23.3 & -23.8 & 0.61 & 2.58 & 1.70 \\
\hline \multirow{2}{*}{4} & $T_{\max }$ & 31.0 & 29.9 & 30.2 & 31.7 & 30.7 & 0.81 & 2.65 & 1.05 \\
& $T_{\min }$ & -28.3 & -28.5 & -28.5 & -29.1 & -28.6 & 0.35 & 1.21 & 0.80 \\
\hline \hline \multirow{2}{*}{ WE\#3 } & {$[H=238$} & $\left.\mathrm{mm}, T_{\mathrm{z}}=1.65 \mathrm{~s}\right]$ & & & & & & \\
\hline \multirow{2}{*}{1} & $T_{\max }$ & 29.7 & 30.2 & 27.8 & 31.2 & 29.7 & 1.43 & 4.80 & 2.2 \\
& $T_{\min }$ & -9.6 & -11.7 & -7.8 & -12.8 & -10.5 & 2.22 & 21.22 & 15.1 \\
\hline \multirow{2}{*}{4} & $T_{\max }$ & 18.1 & 18.4 & 21.2 & 18.7 & 19.1 & 1.42 & 7.44 & 3.5 \\
& $T_{\min }$ & -13.0 & -14.8 & -13.5 & -17.3 & -14.7 & 1.92 & 13.12 & 9.3 \\
\hline \hline
\end{tabular}

The magnitude of the impact pressure was found to vary among runs with a standard deviation of approximately $1.0 \mathrm{kPa}$ for PT\#8 and $0.122 \mathrm{kPa}$ for PT\#16 (Table 8), which corresponds to the CV of up to $9 \%$, or about 3 times higher than that for the maximum wave elevation in the same event.

Table 8: Impact pressures, $P_{\mathrm{i}}$, [kPa] measured in four repeated runs at PT\#8 and PT\#16 due to wave event WE\#2 $\left[H=260 \mathrm{~mm}, T_{z}=1.37 \mathrm{~s}\right]$.

\begin{tabular}{ccccccccc}
\hline \hline PT\# & Run 1 & Run 2 & Run 3 & Run 4 & Mean & $\sigma$ & CV (\%) & $\alpha(-)$ \\
\hline 8 & 12.08 & 11.96 & 12.32 & 10.05 & 11.6 & 1.05 & 9.00 & 3.56 \\
16 & 1.34 & 1.62 & 1.57 & 1.51 & 1.51 & 0.12 & 8.00 & 3.16 \\
\hline \hline
\end{tabular}

The differences in the variability of the measured responses are expected and they can be related to the response physical non-linearity. The highly non-linear 
responses are bound to have higher uncertainty and are therefore more difficult to reproduce accurately. In fact, any TLP response X may be considered as a probabilistic variable which depends on the wave elevation $Z$ in the generic form:

$$
X=K(a, b, c, \ldots) Z^{\alpha}
$$

Here $K(a, b, c, \ldots)$ is the coefficient, which depends on all physical parameters of the model and a particular wave event, excluding the wave elevation Z. By linearizing the above function in the vicinity of its expected value and taking its variance, the following relation can be shown:

$$
C V(X) \approx \alpha C V(Z)
$$

Therefore, although the exact functional form of the response is unknown, the extent of its nonlinear dependence on the wave elevation (or other wave properties proportional to wave elevation) can be inferred from the measured CV values. The power values, $\alpha$, are also shown in the respective tables. It can be seen that the maximum tendon tensions behave approximately linear with the wave elevation in WE\#2 whilst higher non-linearity is inferred for WE \#3, especially for the minimum tensions. Similarly, the CV for the impact pressures (Table 8), behave non-linearly and are consistent with the power $\propto$ between 3 and 4 . The variability of the impact pressure measured by all transducers in different test runs can be seen from the boxplot produced in Figure 11 for wave event WE\#2. A particularly high variability (CV up to $\approx 70 \%$ or $\alpha$ up to 30 ) was obtained for the forward part of the deck, and pressure locations PT\#1 and PT\#6. This indicates an extremely high non-linearity and that a larger number of test runs are required to produce more consistent values of the impact pressure for such locations. It is worth mentioning that the presence of 
small scale hydrodynamic flow instability and turbulence might have a role in the observed variability in the measurements of wave-in-deck slamming pressure at a discrete point. Based on the platform column diameter Reynolds number was estimated to be $1.7 \times 10^{5}$ and $1.2 \times 10^{5}$ for WE\#2 and WE\#3, respectively. Boxplots corresponding to all wave events analysed in this study are given in Appendix.

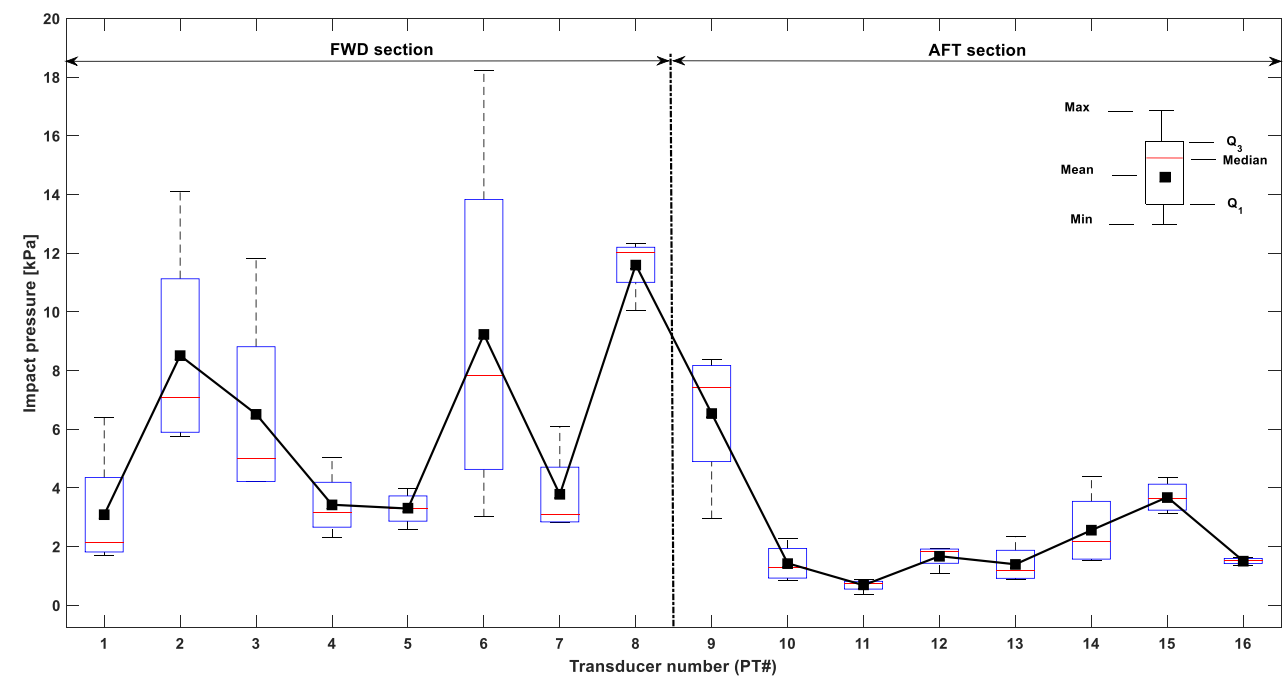

Figure 11: Boxplots showing variation in impact pressure at different pressure transducers due to wave event WE\#2 $\left[\mathrm{H}=260 \mathrm{~mm}, \mathrm{~T}_{\mathrm{z}}=1.37 \mathrm{~s}\right]$.

\section{Results and discussion}

A complete set of results for all wave events, including time histories of wave elevations at deck leading edge (LE) and trailing edge (TE), surge motion of the platform and tendon tensions are presented in Appendix. In this section, only selected results are discussed to support the interpretation the observed TLP behaviour.

\subsection{Model's dynamics due to wave-in-deck impact}

Time histories of the wave elevations at the deck leading and trailing edge, LE and TE, platform surge motion and tendon tensions are shown in Figure 12 for wave 
event WE \# 1, as an example. For the interpretation of the platform dynamics, it is convenient to introduce several parameters, which are schematically illustrated in Figure 13. In this figure, the position of the deck is defined in the local coordinate system $(x, z)$ with its origin at the deck LE in the static condition. The following parameters are defined:

- $t_{o}$ is the initial time of contact when the wave comes in contact with the LE.

- $t_{i}$ is the time when the up-wave tendon experiences maximum tension in which the wave crest comes in contact with the LE.

- $t_{m}$ is the end time of contact with the LE when the wave leaves the LE and propagates along the deck.

- $t_{f}$ is the end time of contact with TE when the wave leaves the deck.

- $x(t)$ is the horizontal coordinate of the deck LE relative to the static condition at the corresponding time instances.

- Time of the up-wave tendon tension build up $d t=t_{i}-t_{o}$.

- Time of interaction with LE: $d t_{L E}=t_{m}-t_{o}$.

- Platform horizontal (surge) velocity at the initial contact $U_{o}$.

- Platform surge velocity at time of maximum tension in the up-wave tendon $U=d x / d t$

- The relative horizontal velocity of the wave crest and the platform $u_{r}=$ $u-U$. The horizontal velocity of the wave crest used in this parameter is calculated approximately (Section 4.3), which is sufficient for the purpose of comparing it with the surge velocity of the platform.

With reference to Figure 12 and Figure 13, the behaviour of the platform due to the wave-in-deck event can be described in terms of the four stages: 
- At time $t_{o}=31.74 \mathrm{~s}$ (Figure 12), the wave contacted the deck LE at $z=$ $a_{0}=120 \mathrm{~mm}$. The deck was at $x_{o}=-61.28 \mathrm{~mm}$ as the model was offset towards the wave and moving in the positive $x$-direction (along with the wave) with $U_{o}=0.09 \mathrm{~m} / \mathrm{s}$. The up-wave tendon (Leg\#1) came under increased tension $T^{\prime}=T_{o}+\Delta T \approx 37.40 \mathrm{~N}$.

- At time $t_{i}=31.90 \mathrm{~s}$ (Figure 12), the up-wave tendon came under maximum tension $\left(T_{\max }=48.00 \mathrm{~N}\right)$ when the wave crest was still in contact with the deck LE at $x_{i}=-19.95 \mathrm{~mm}$. The model was now moving with a higher velocity $U=d x / d t \approx 0.30 \mathrm{~m} / \mathrm{s}$ and the relative horizontal velocity $\left(u_{r}=u-U\right)$ between the wave crest and the model was $0.39 \mathrm{~m} / \mathrm{s}$. At time $t_{m}=32.03 \mathrm{~s}$, the wave crest was leaving the deck LE, which was at $x_{m}=21.40 \mathrm{~mm}$. During the time interval $\left[t_{m}-\right.$ $\left.t_{i}\right] \approx 0.13 \mathrm{~s}$, the tension in the up-wave tendon decreased rapidly to approximately the same value $T^{\prime}$ that was experienced at the initial contact. As such, the impulse-like loading in the up-wave tendon lasted for $0.28 \mathrm{~s}$ at model scale ( $3.13 \mathrm{~s}$ at full scale).

- At time $t_{f}=32.03 \mathrm{~s}$ (Figure 12), the wave was tangentially leaving the deck TE, which was at $x_{f}=93.40 \mathrm{~mm}$. Hence the platform travelled $154.68 \mathrm{~mm}$ (or $19.33 \mathrm{~m}$ at full scale) in wave direction over the duration of wave impact; this surge motion represents only $4.5 \%$ of the wave length. The down-wave tendon (Leg\#4) was under very low tension $(3.60 \mathrm{~N})$ while the tension in the up-wave tendon also reduced $(24.93$ $\mathrm{N})$ and the model experienced large pitch motion of approximately $0.80^{\circ}$. 
It can be seen in Figure 12 that the minimum tensions in both tendons occurred after time $t_{f}$ when the down-wave tendon became slack. This was followed by a rapid increase in tension and a number of ringing oscillations in the down-wave tendon. The up-wave tendon also showed ringing response with smaller amplitudes.
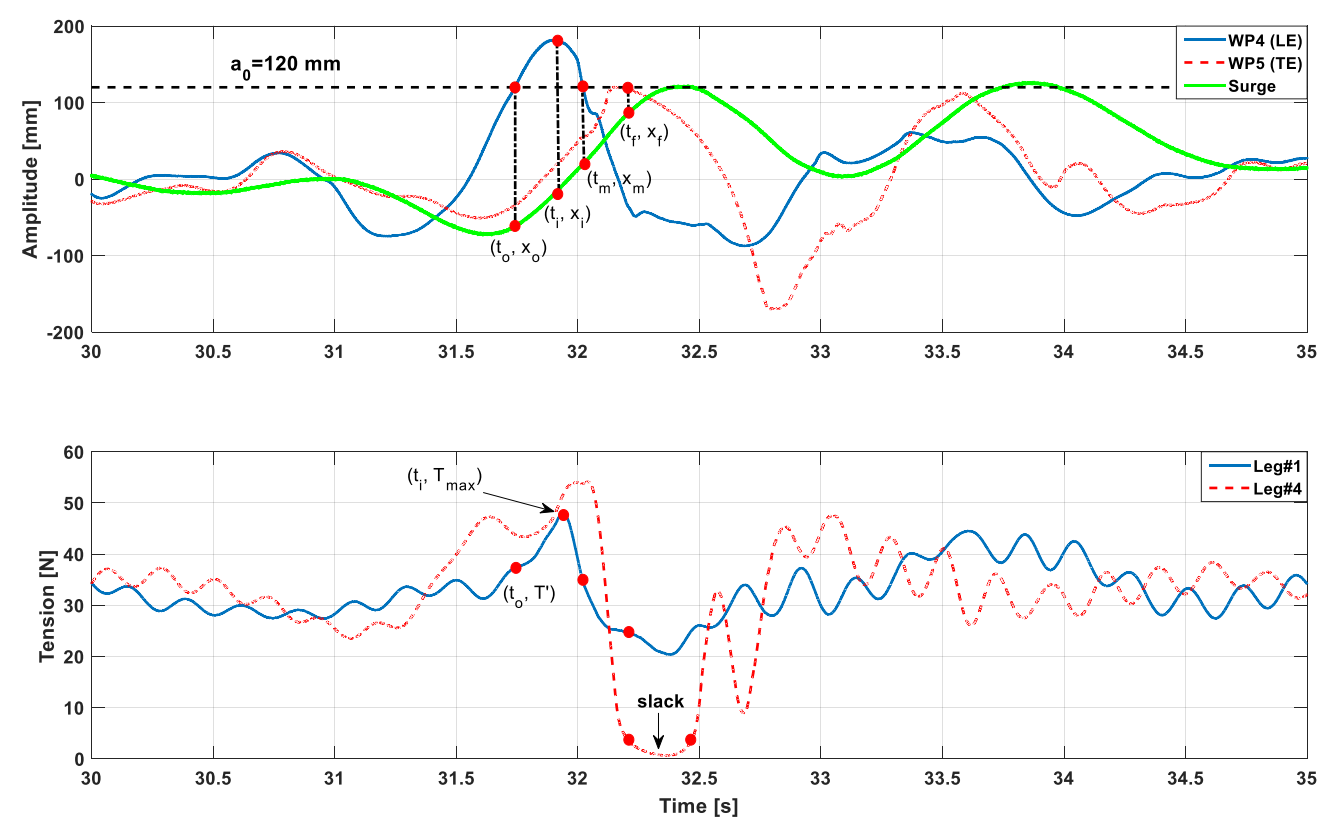

Figure 12: Simultaneous measurements corresponding to wave event WE\#1 [ $H=231 \mathrm{~mm}, T_{\mathrm{z}}=$ $1.48 \mathrm{~s}$ ]: wave elevations at WP4 and WP5 and surge motion (top); tension in the up-wave and down-wave tendons (bottom).

Table 9 summarises all the key parameters of the wave and model response for all wave events averaged over multiple repeated runs. The following observations were made:

- In all wave impact events, at the time of the initial contact of the wave with the deck, the model was always moving in the positive $x$-direction; the model velocity $U_{o}$ was the range of $0.09-0.32 \mathrm{~m} / \mathrm{s}$. Even if the platform was offset towards the waves, it was still moving with the waves. This behaviour was likely to be caused by the wave-induced hydrodynamic forces on the columns and pontoons immediately prior to the deck impact. 


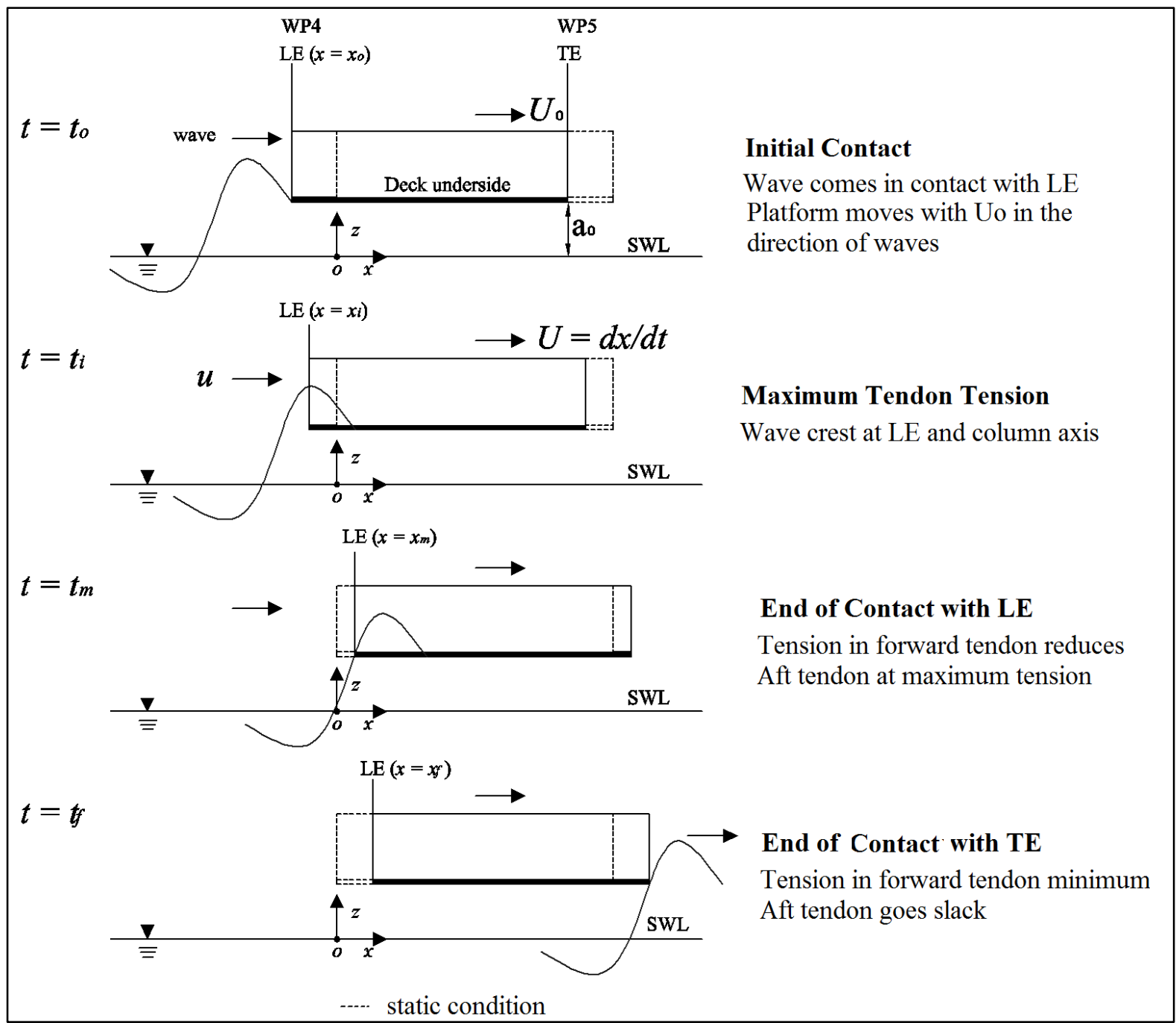

Figure 13: Sketch definition showing the interaction between wave event WE\#1 and the topside deck structure both moving in the positive $x$-direction. The time sequence is given from top to bottom [not to scale].

Table 9: Parameters of wave and model response during wave-in-deck impact.

\begin{tabular}{cccccccccc}
\hline \hline $\begin{array}{c}\text { Wave } \\
\text { event } \\
(\text { WE\#) }\end{array}$ & $T_{\mathrm{z}}(\mathrm{s})$ & $u(\mathrm{~m} / \mathrm{s})$ & $x_{\mathrm{o}}(\mathrm{mm})$ & $x_{\mathrm{i}}(\mathrm{mm})$ & $d t(\mathrm{~s})$ & $\begin{array}{c}U_{\circ} \\
(\mathrm{m} / \mathrm{s})\end{array}$ & $\begin{array}{c}U \\
(\mathrm{~m} / \mathrm{s})\end{array}$ & $\begin{array}{c}u_{\mathrm{r}} \\
(\mathrm{m} / \mathrm{s})\end{array}$ & $\begin{array}{c}d \mathrm{tLE}_{\mathrm{L}} / T_{\mathrm{z}} \\
(\%)\end{array}$ \\
\hline 1 & 1.48 & 0.65 & -61.28 & -19.95 & 0.16 & 0.09 & 0.26 & 0.39 & 19 \\
2 & 1.37 & 0.85 & -3.44 & 20.64 & 0.06 & 0.32 & 0.37 & 0.48 & 9 \\
3 & 1.65 & 0.60 & 27.17 & 62.59 & 0.09 & 0.30 & 0.39 & 0.21 & 9 \\
4 & 1.35 & 0.72 & 10.88 & 34.38 & 0.09 & 0.24 & 0.27 & 0.45 & 11 \\
5 & 1.76 & 0.42 & -33.46 & -15.27 & 0.12 & 0.09 & 0.15 & 0.27 & 16 \\
6 & 1.73 & 0.37 & -55.83 & -36.55 & 0.08 & 0.14 & 0.24 & 0.13 & 10 \\
8 & 1.46 & 0.77 & -47.43 & -5.86 & 0.14 & 0.16 & 0.30 & 0.47 & 20 \\
\hline \hline
\end{tabular}


- In all wave events, the model's surge velocity increased to a higher value of $U=0.15-0.39 \mathrm{~m} / \mathrm{s}$ during the active phase of the wave-indeck event $(d t)$. As a result, the relative horizontal velocity, $u_{r}$, between the wave crest and the deck was always smaller compared with the initial moment, and with a similar situation for a fixed structure. This reduction in the relative velocity was of the order of $50 \%$ on average, compared with the wave particle velocity $u$ in the undisturbed wave crest.

- On average, the wave remained in contact with the deck LE over the time of approximately $13 \% T_{z}$, and during this time, the up-wave tendon experienced its peak loading.

- Similar wave events (WE\#2 and WE\#8) were found to cause similar model's dynamics in terms of the relative velocity. However, differences in $d t_{L E} / T_{Z}$ were obtained, which could be attributed to the difference in $T_{z}$ and the initial position $x_{o}$ between various wave events.

- In all wave events tested, the wave crest exceedance measured at the deck leading edge was always higher than that at the trailing edge. This indicates the presence of diffraction (distortion of the impacting wave profiled) caused by the deck itself.

Figure 14 shows the interaction between WE\#1 and the model during the water-entry and the water-exit phases. 


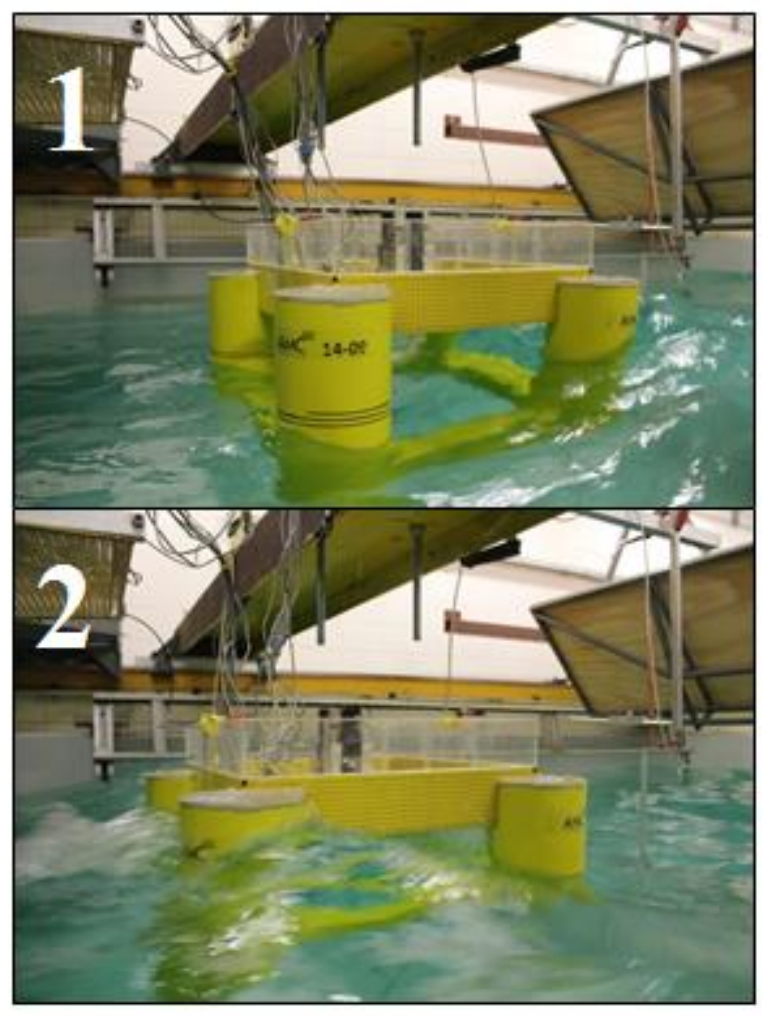

Figure 14: Photograph showing wave impact at the TLP model due to wave event WE\#1: (1) water entry at time $\approx t_{o} ;(2)$ water exit at time $\approx t_{f}$ (wave propagating from right to left).

\subsection{Slack tendon situations}

The slack tendon situations were observed in the down-wave tendon due to wave events WE\#1, WE\#2 and WE\#8. The time period during which the down-wave tendon remained slack ( $\left.t_{\text {slack}}\right)$ was found to be between $0.25 \mathrm{~s}$ and $0.34 \mathrm{~s}$ at model scale or $3-4 \mathrm{~s}$ in full scale (refer Figure 12, Fig.A 3, and Fig.A 15); these times are summarised in Table 10. Consistent with the slack tendon measurements, a relatively large pitch response was measured with the maximum pitch angles in the down-wave direction between $0.65^{\circ}$ and $0.80^{\circ}$. Johannessen et al. (2006) have also observed a large pitch angle (approximately $0.3^{\circ}$ ) during model testing of SNORRE A TLP when the model was subjected to a large deck exceedance. Furthermore, Johannessen et al. conducted CFD simulations for SNOREE A TLP at full scale using two extreme regular wave conditions including $\mathrm{H}=27.9 \mathrm{~m}$ and $36.4 \mathrm{~m}$. At $\mathrm{H}=$ 
$36.4 \mathrm{~m}$ (approximately $3 \mathrm{~m}$ deck exceedance when wave diffraction and upwelling effects are considered), the platform pitch motion was found to be approximately $0.3^{\circ}$. Since the equivalent full scale deck exceedance of WE\#1, WE\#2 and WE\#8 reported in the present investigation are larger than $3 \mathrm{~m}$ at full scale, which was approximately twice as large as that tested by Johannessen et al., the larger maximum pitch response are justified.

The measurements of tendon tensions, wave elevation at LE and TE suggest that these wave events must have caused significant downward forces on the model, which originated from the deck impact. Findings from other recent studies (Abdussamie et al, 2016; Scharnke et al, 2014; Scharnke and Henning, 2015) into the wave-in-deck impact problems of fixed decks identified the downward force on the deck alone, the magnitude of which can be as large as the upward force component. Scharnke et al (2014) and Abdussamie et al. (2016) attributed the large magnitude of the downward force to the added mass surrounding the deck structure, in both $x$ and $z$ directions, which is accelerated downwards at this time. This can be interpreted as a "suction force" due to substantial amount of water flowing downwards from the deck underside, when the wave leaves the deck after the impact. The instantaneous reduction in buoyancy of the aft columns subsequent to the deck impact could also be a contributing factor.

Table 10: Slack tendon situations in the down-wave tendon.

\begin{tabular}{ccccc}
\hline \hline $\begin{array}{c}\text { Waver event } \\
\text { (WE\#) }\end{array}$ & $\begin{array}{c}\text { Minimum tension, } \\
\boldsymbol{T}_{\min }[\mathbf{N}]\end{array}$ & $\begin{array}{c}\text { Slackness duration, } \\
\boldsymbol{t}_{\text {slack }}[\mathbf{s}]\end{array}$ & $\begin{array}{c}\boldsymbol{t}_{\text {slack }} / \boldsymbol{T}_{\boldsymbol{z}} \\
{[\%]}\end{array}$ & $\begin{array}{c}\text { Max } \\
\mathbf{p i t c h} \\
\text { angle }\left({ }^{\circ}\right)\end{array}$ \\
\hline 1 & 0.46 & 0.30 & 20 & 0.80 \\
2 & 1.78 & 0.34 & 25 & 0.67 \\
8 & 1.41 & 0.25 & 17 & 0.65 \\
\hline \hline
\end{tabular}




\subsection{Tendon ringing response}

In all wave events, the TLP model was found to experience high-frequency vertical motions with the period close to its natural heave period $(0.225 \mathrm{~s})$, known as "ringing". The short-term transient ringing response was observed in both up-wave and down-wave tendons. The energy spectra of both tendon tensions for wave event WE\#1 are presented in Figure 15, for the time window of $31.9 \mathrm{~s}-40 \mathrm{~s}$ (starting from $t_{i}$ in Figure 12). The figure shows significant energy around the heave natural frequency, whereas the spectrum of the wave elevation (measured by WP 4) has almost no content at this frequency. This indicates that the tendon ringing was caused mostly by the wave-in-deck impact.
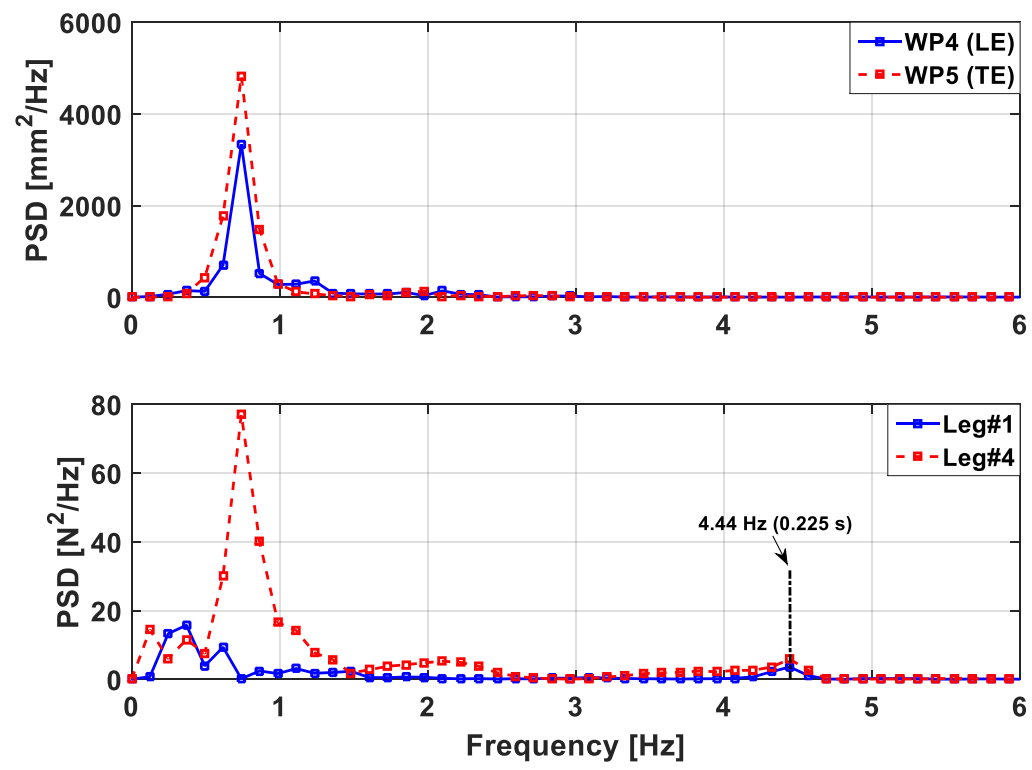

Figure 15: Power density spectra of wave elevations (top) and tendon tensions (bottom) during and subsequent to the deck impact due to WE\#1 $\left[H=231 \mathrm{~mm}, T_{\mathrm{z}}=1.48 \mathrm{~s}\right]$.

The extended set of results, presented in the Appendix, indicates that ringing response was presented in almost all wave events. In the cases when the TLP was subjected to a single wave-in-deck impact, the ringing was noticeable in the tendon time history only after the point of minimum tendon tension. In the rare cases where the TLP was subjected to two consecutive wave-in-deck impacts, the ringing 
response caused by the preceding wave was found to be noticeable along the entire time history of the second impact after the point of minimum tendon tension. In some cases, the high-frequency content in the tendon tensions was detected before or even without the wave-in-deck impact event. In these situations, it is rather difficult to separate the ringing response caused by the wave-in-deck events from "springing" response caused by the sum-frequency second order wave loading. Because such analysis is outside the scope of this study, the high-frequency motions and dynamic tensions of the platform will be generally referred to as "ringing" and more specific explanations provided where possible.

In order to quantify the ringing response associated with each wave event the following approach was used:

- The ringing duration was defined by the number of oscillations observed in the time history of the tendon tension until the oscillatory tension response approximately vanished;

- The maximum and minimum magnitude of each observed oscillation were extracted and the tension range $\left(T_{r}\right)$ calculated $\left(T_{r}=\right.$ maximum tension - minimum tension); and

- The tension ranges were then normalised by the tendon pretension (normalised ringing tendon tension $T_{r}^{*}=T_{r} / T_{0}$ ) and grouped according to the number of occurrences.

Examples of the ringing response identified in wave events WE\#1 - WE\#8 for the up-wave and down-wave tendons are presented in Figure 16. 

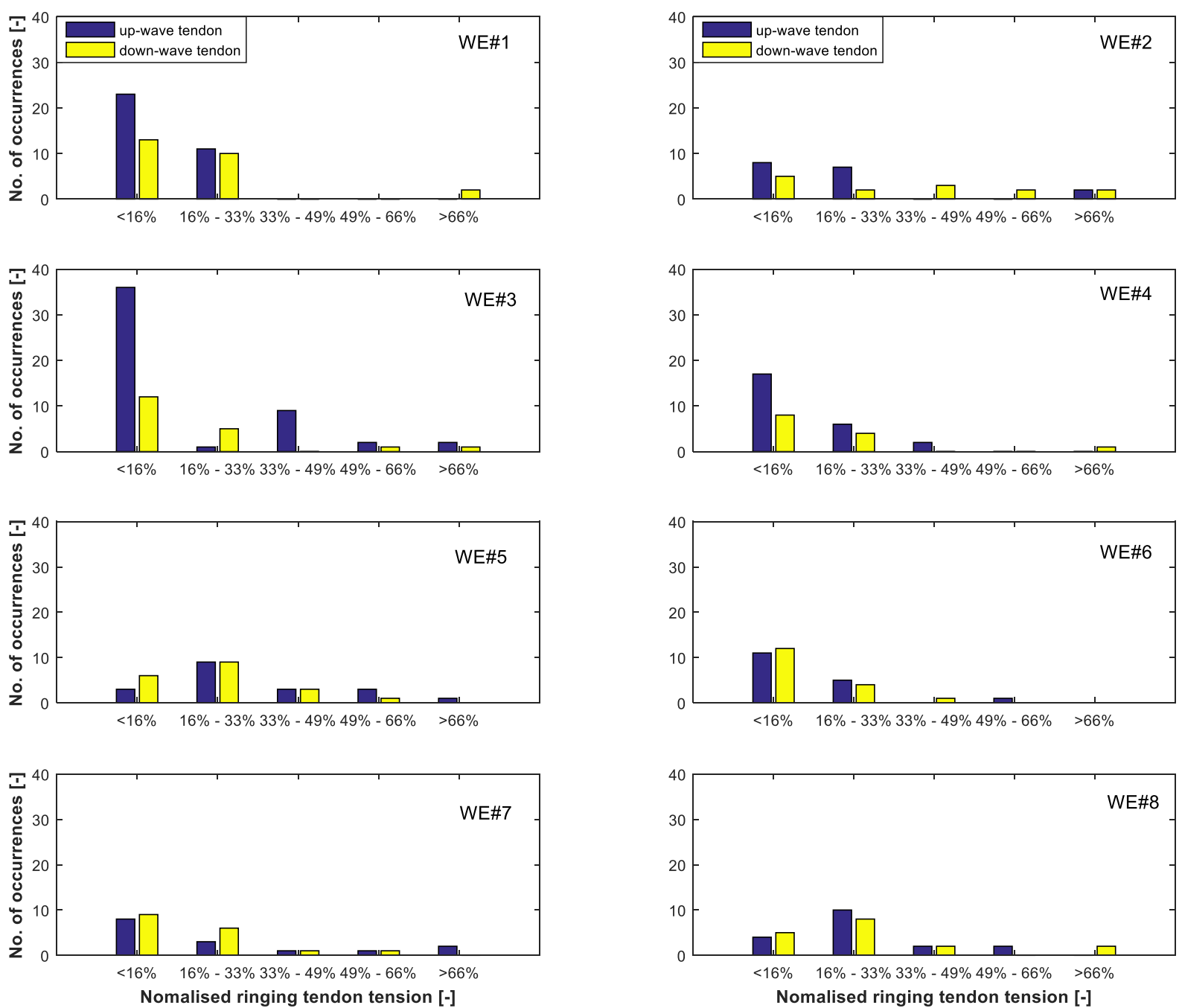

Figure 16: Normalised ringing tension in the up-wave and down-wave tendons caused by the examined wave events versus the number of occurrences.

In most cases, as expected, the number of occurrences $(N)$ was inversely proportional to the tendon tension range for both tendons. Wave events WE\#3 and WE\#1 caused the largest number of ringing tension occurrences, in particular in the up-wave tendons, with ringing tension range exceeding the $15 \%$ of the tendon pretension. A particular feature of wave event WE \#3, as seen in Figure 7, was the second successive steep wave, which was the likely cause of a longer oscillatory heave of the platform. This observation revealed that whilst the platform may have 
missed the second deck impact by the successive large wave, this wave may have largely contributed to the extended high-frequency tension response.

On average, the magnitude of ringing range in Leg\#1 and Leg\#4 was found to be almost the same over all wave events. On the other hand, the ringing response observed in the up-wave tendon (Leg\#1) was seen to be more intense than that in the down-wave tendon (Leg\#4). This observation correlates well with the higher values of slams pressure measured over the front section of the deck underside in most cases.

\subsection{Maximum and minimum tension}

The magnitudes of maximum and minimum tendon tension measured in repeated runs were averaged and summarised in Table 11 for all wave events. The maximum tensions in the up-wave and down-wave tendons corresponding to each wave event are of approximately the same level, except for wave events WE\#1 - 3, without a clear trend of higher tension being experienced by the up-wave or down-wave tendon. The minimum tension in Leg\#4 is significantly lower than that in Leg\#1, particularly in wave events WE\#1, WE\#2 and WE\#8, when the down-wave tendon became slack. In order to compare the extreme tensions, they were normalised using the tendon pretension, $T_{0}=30.4 \mathrm{~N}$. The normalised maximum tension $\left(T^{*}\right.$ max $=$ $\left.T_{\max } / T_{\mathrm{o}}\right)$ and minimum tension $\left(T^{*} \min =T_{\min } / T_{\mathrm{o}}\right)$ are shown in Figure 17 against the wave steepness. In most conditions, $T^{*}$ max appears to increase with the wave steepness, although the trend is not very noticeable. Notably, two extreme events WE\#2 and WE\#3 produced the maximum tendon tension of approximately 2.5 times the pretension. It is important to note that, out of all wave events studied, the maximum tendon tension occurred in the up-wave tendon in wave event WE\#2, 
which is characterised by the highest wave steepness rather than the highest wave crest.

With respect to the minimum tension, there is a slight trend for the down-wave tendon to experience less tension as the wave steepness increases. The minimum tension in the up-wave tendon does not show a noticeable change. As already mentioned, wave events WE\#1, 2 and 8 caused lower minimum tension among other wave events which could be attributed to the large pitch angle observed during such wave events (see Table 10). Another observation is that out of all events studied, that minimum tendon tension occurred in wave event WE\#1, which is characterised by moderate crest height and also moderate wave steepness. This indicates that the selection of a particular wave event which may produce the highest or the lowest tension (including the slack tendon situation), as may be required for the TLP design, is not a straightforward task, and a range of wave events or other special criteria may need to be considered.

Table 11: Average maximum and minimum tensions measured in the up-wave tendon (Leg\#1) and down-wave tendon (Leg\#4) for different wave events.

\begin{tabular}{cccccccc}
\hline \hline & & & & \multicolumn{3}{c}{ Tension in Leg\#1 } & \multicolumn{2}{c}{ Tension in Leg\#4 } \\
WE\# & $H[\mathrm{~mm}]$ & $T_{\mathrm{z}}(\mathrm{s})$ & $S(-)$ & \multicolumn{2}{c}{$(\mathrm{N})$} & \multicolumn{2}{c}{$(\mathrm{N})$} \\
\cline { 4 - 8 } & & & & $T_{\max }$ & $T_{\min }$ & $T_{\max }$ & $T_{\min }$ \\
\hline 1 & 231 & 1.48 & 0.068 & 47.08 & 18.83 & 54.33 & 0.46 \\
2 & 260 & 1.37 & 0.089 & 79.69 & 6.66 & 61.11 & 1.78 \\
3 & 238 & 1.65 & 0.057 & 60.13 & 19.92 & 49.51 & 15.75 \\
4 & 227 & 1.35 & 0.080 & 39.90 & 28.70 & 43.73 & 14.90 \\
5 & 186 & 1.76 & 0.040 & 50.48 & 13.04 & 45.30 & 13.43 \\
6 & 168 & 1.73 & 0.037 & 38.30 & 21.67 & 45.82 & 15.27 \\
7 & 191 & 1.44 & 0.059 & 53.78 & 22.00 & 49.64 & 8.00 \\
8 & 261 & 1.46 & 0.079 & 67.63 & 17.99 & 67.34 & 1.41 \\
\hline \hline
\end{tabular}



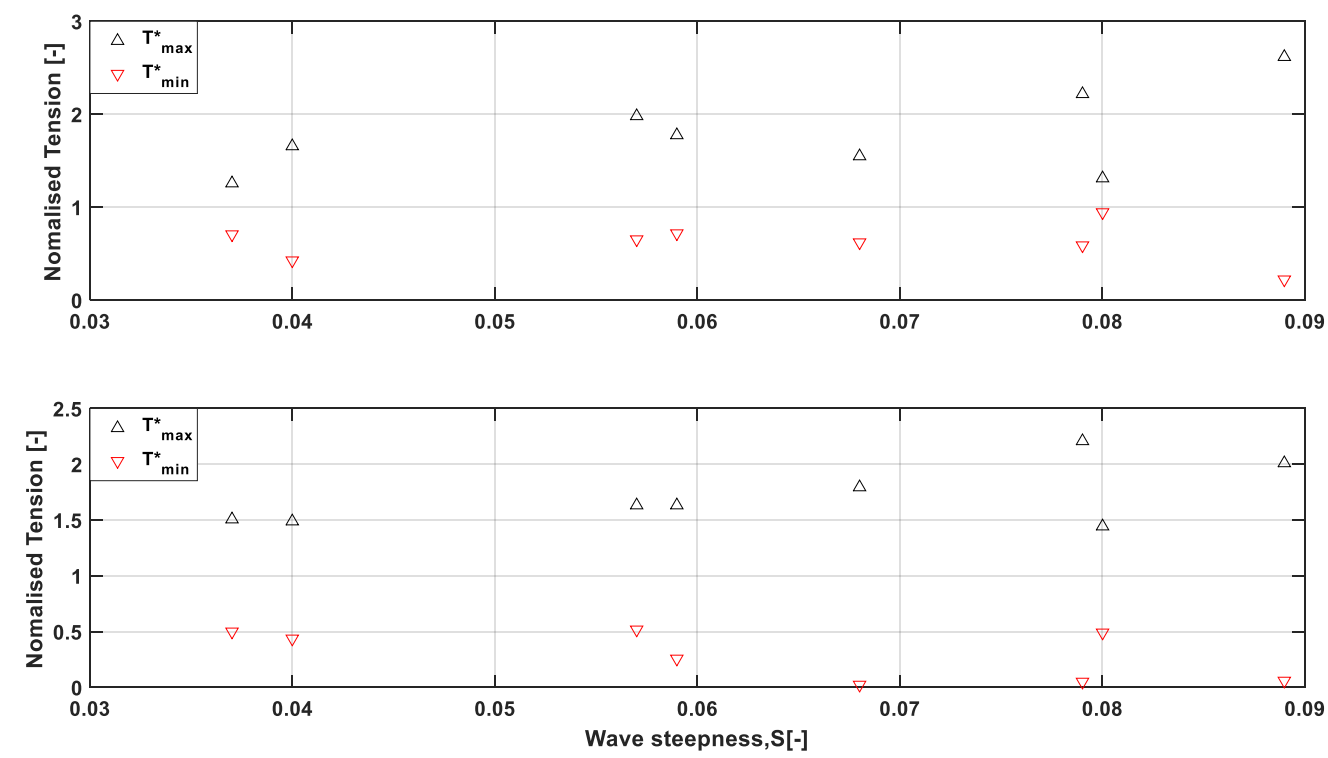

Figure 17: Average normalised tension $\left(T^{*}{ }_{\max }=T_{\max } / T_{0}, T^{*}{ }_{\min }=T_{\min } / T_{0}, T_{0}=30.4 \mathrm{~N}\right)$ versus wave steepness: up-wave tendon, Leg\#1 (top); down-wave tendon, Leg\#4 (bottom).

\subsection{Wave-in-deck slamming pressures}

The measured pressure values $P_{i}$ were normalised by the hydrostatic wave pressure:

$$
P_{i}^{*}=\frac{P_{i}}{\rho g \eta_{c}}
$$

where $\rho$ is the density of water, $g$ is the acceleration due to gravity, $\eta_{c}$ is the crest height for each wave events measured by WP3 in front of the model. The normalised maximum pressures averaged over the repeated runs are presented for all wave impact events in Figure 18 through Figure 21 for the deck zones I - IV, respectively (for the definition of the zones, refer to Table 3 ). When the pressure is considered as a function of the relative deck exceedance $\epsilon=1-a_{0} / \eta_{c}$, the increasing trend is evident as the relative exceedance increases, which corresponds to increasing wave crest height compared with the still water deck clearance $a_{0}$. The same figures compare the model test results with the theoretical result obtained by 
Wang (1970) for the maximum wave-induced uplift pressure on a horizontal flat plate. Wang's result for the maximum wave impact pressure reduces to a simple equation:

$$
P_{i}^{*}=\frac{P_{i}}{\rho g \eta_{c}}=\pi \tanh (k d) \sqrt{1-\left(\frac{a_{0}}{\eta_{c}}\right)^{2}}
$$

where $d$ is the water depth, $k$ is the wave number $(=2 \pi / \lambda)$ and $\lambda$ is the wave length. For the individual wave events, these quantities are given in Table 5. Because Wang's treatment was limited to a fixed flat plate, its applicability to floating structures is in question. However, the comparison in Figure 18 through Figure 21 shows that the overall trend of the measured pressures is generally similar to that given by Wang's equation, even though a large spread of measured results is evident. A possible explanation for this observation may be in the fact that the vertical (heave) response of a TLP is always small and its horizontal (surge) excursion over the duration of the impact is also small compared with the wave length (Section 6.1). Therefore, although the wave-induced TLP responses do affect the impact pressure and Wang's equation is not be strictly applicable for each particular event, when several impact events with different wave properties and phases are considered the trend for the average deck impact pressure tends to become close to that for a fixed structure, but with a broader variability. Further work is required to confirm or dismiss this suggestion.

The experimental results indicate that the impact pressure in the forward part of the deck is higher than in the aft part except PT \#1, 16 and \#2, 15 (near the columns and ends of the deck) where this trend is reversed. By comparing pressure between the areas of forward and aft columns (PT \#1, 16 and \#2, 15), in most cases, 
pressure near the aft end is higher than that near the front end (i.e., pressure at PT\#16 is larger than that at PT\#1; and similarly for PT\#15 and PT\#2). This could be caused by the wave upwelling being larger around the aft columns and/or the effect of platform set-down as the platform offsets.
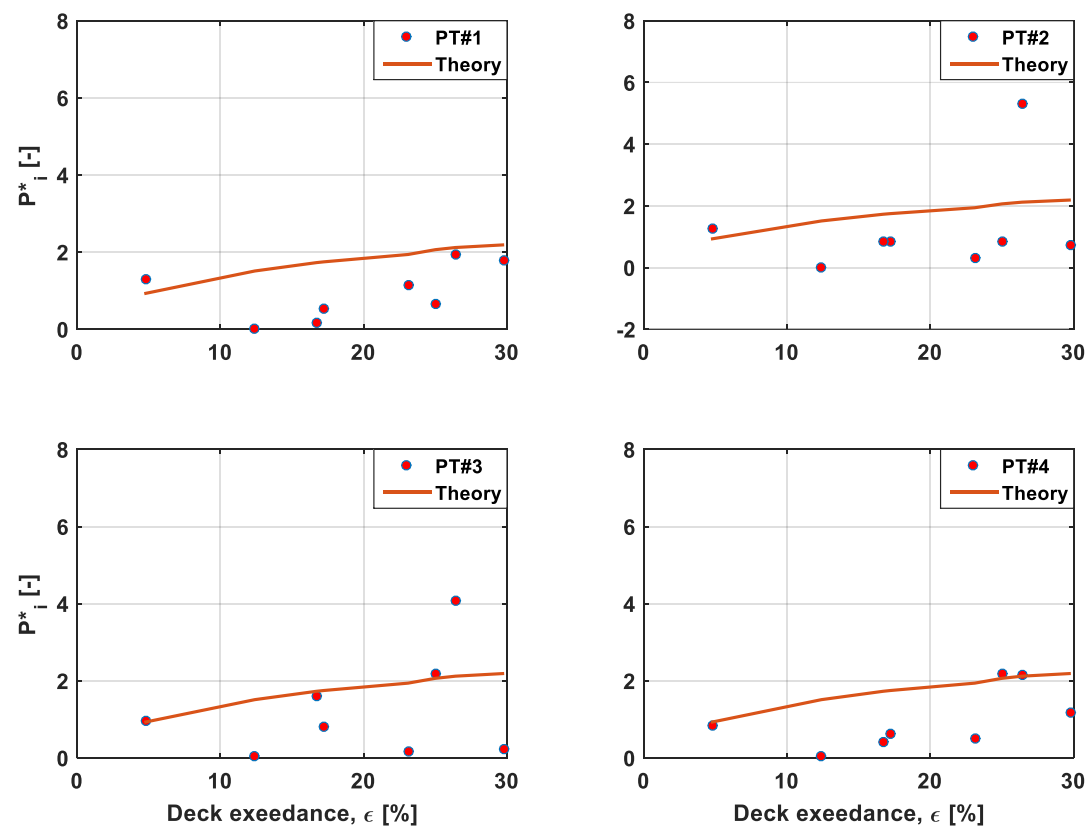

Figure 18: Normalised slam pressure distribution in the zone I (around the forward columns).
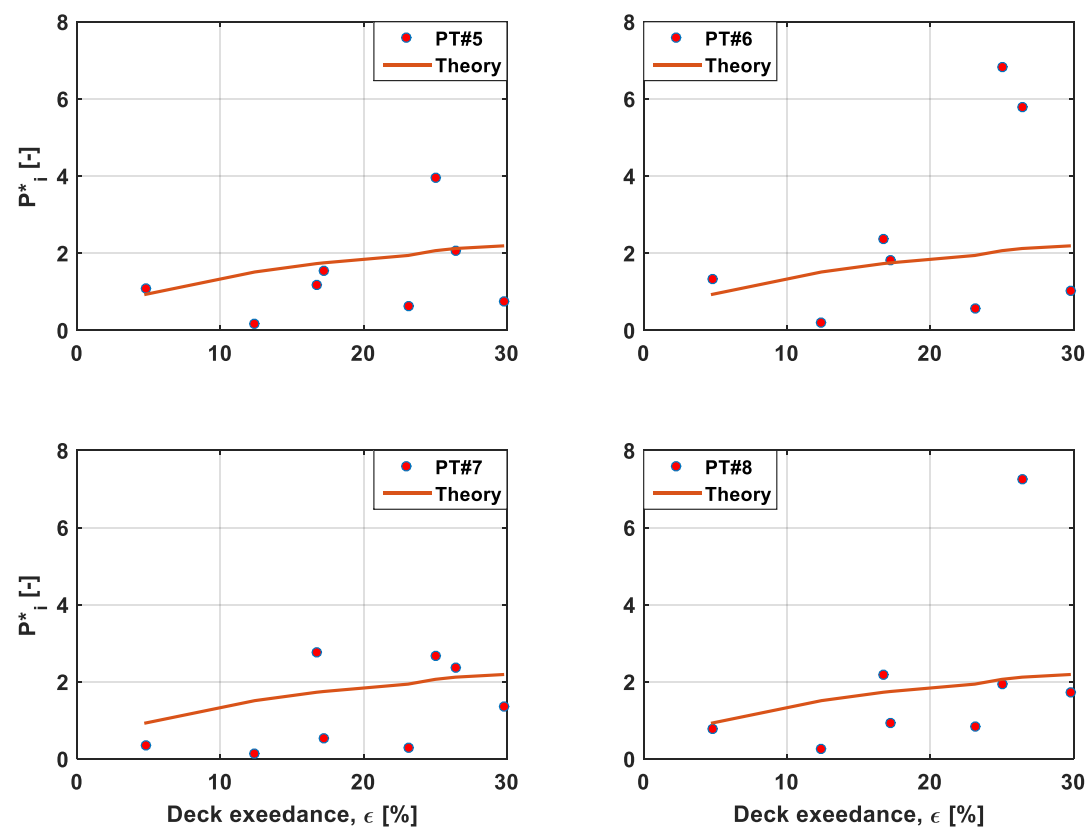

Figure 19: Normalised slam pressure distribution in the zone II (forward middle section). 

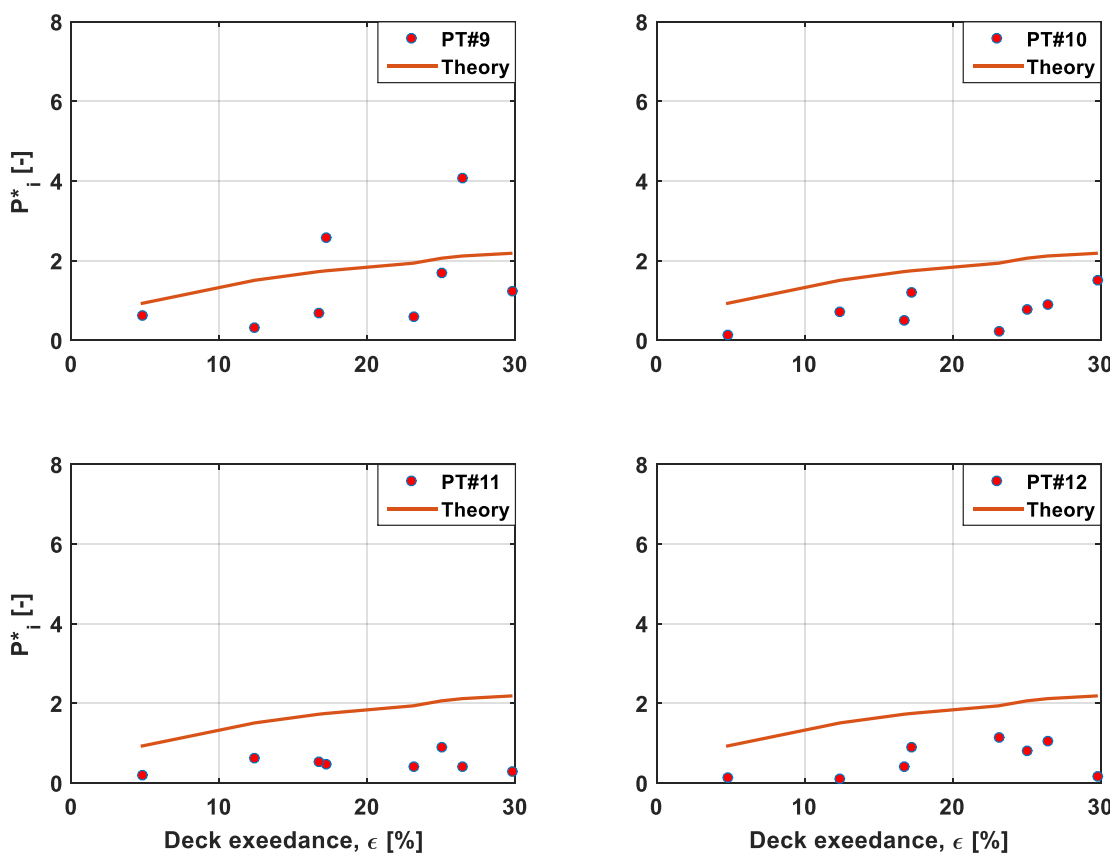

Figure 20: Normalised slam pressure distribution in the zone III (aft middle section).
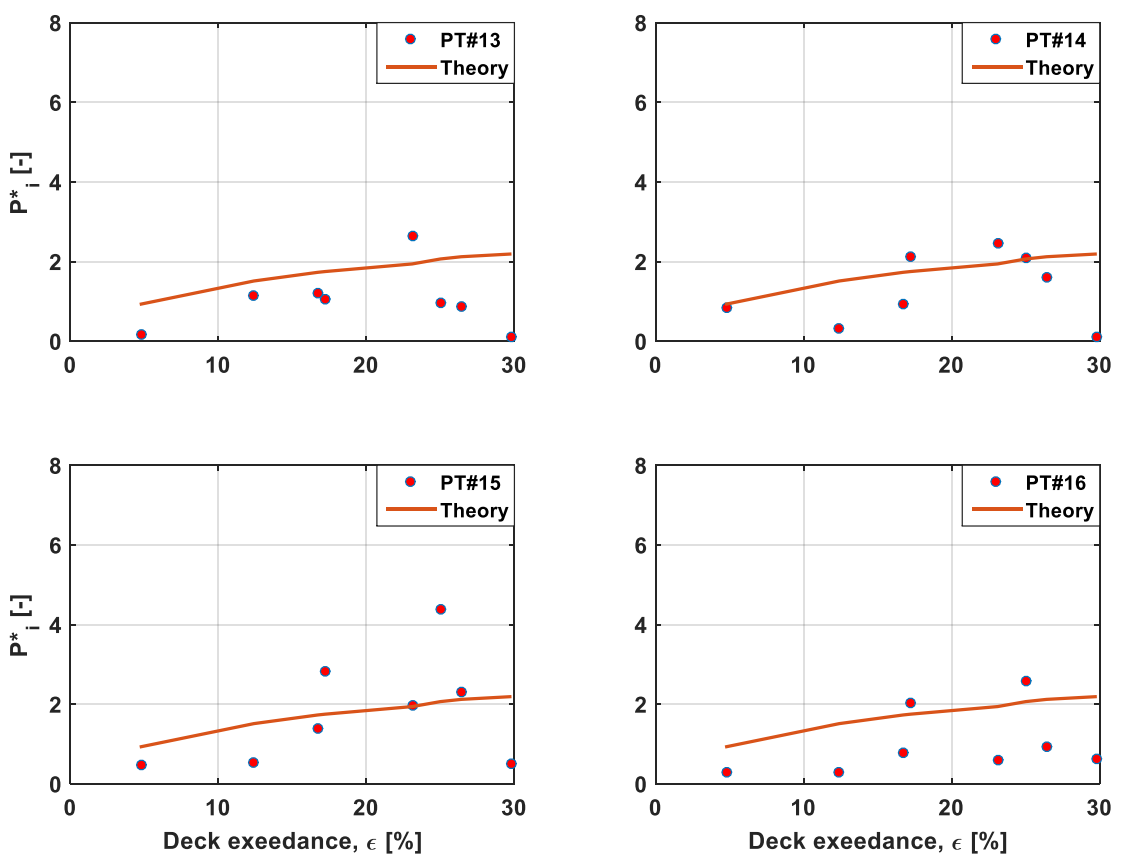

Figure 21: Normalised slam pressure distribution in the zone IV (around the aft columns). 


\subsection{Correlation between tendon tensions and impact pressure}

Maxima of tendon tensions and localised pressures in the forward and aft regions are presented in Figure 22. The figure suggests that correlation exists between the maximum tendon tension and the localised pressure measured around the columns of the deck underside in the respective part of the structure. In addition to the motion-induced forces, the magnitude of wave-in-deck slamming pressure may significantly contribute in the maximum tendon tensions, as evident from a number of wave events examined in this study. To confirm this finding, more investigations are still required.

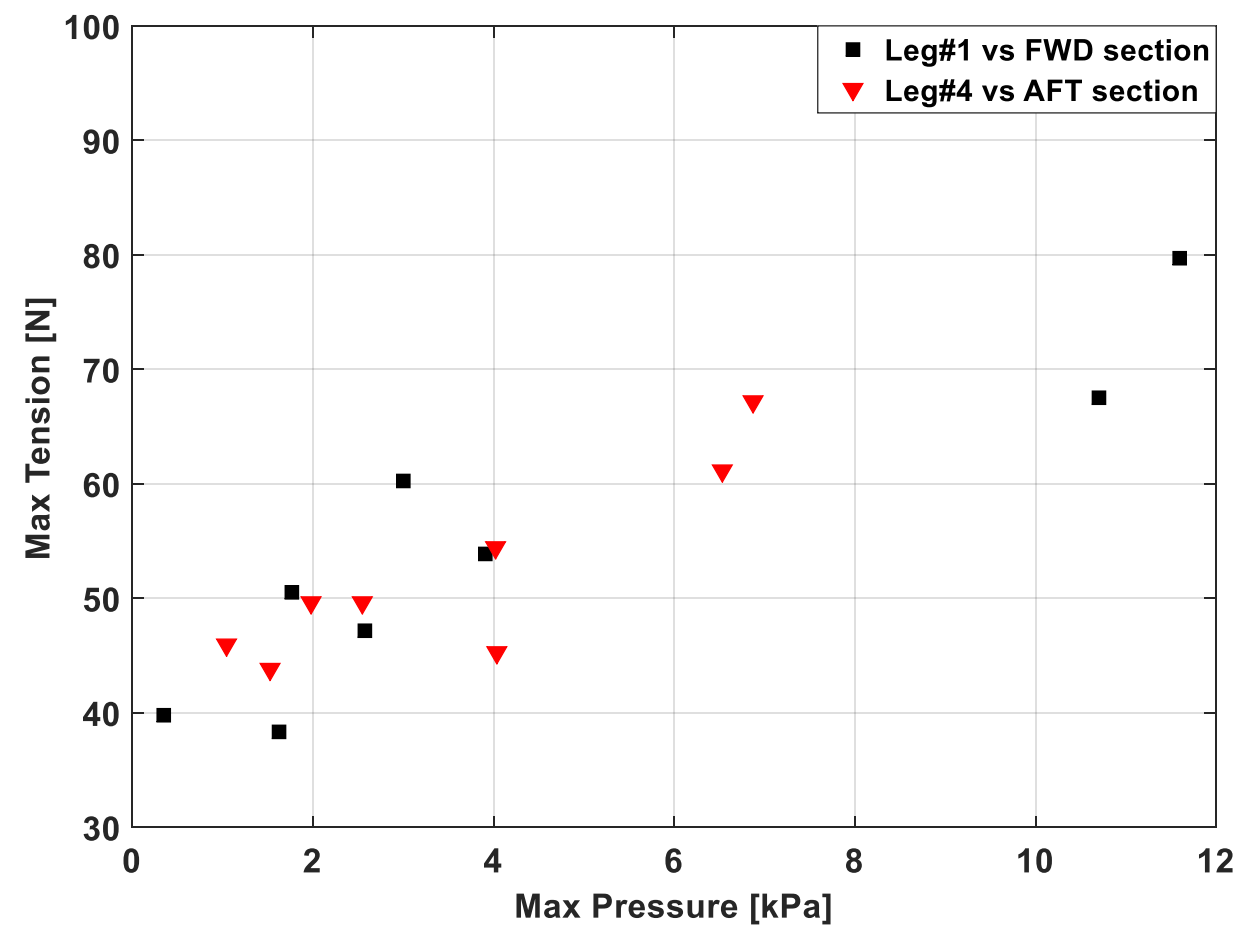

Figure 22: Maximum tension measured in the up-wave tendon (Leg\#1) and down-wave tendon (Leg\#4) versus maximum pressure measured in the forward and aft sections of the deck underside.

\section{Conclusions}

This experimental investigation has provided detailed information on the global behaviour of a TLP due to wave-in-deck events in abnormal waves, which can be used for calibrating analytical tools and CFD models. The model test study is 
focused on the wave-structure interaction irregular waves, without the presence of the wind and current. Analysis of the measurements and observations of the model response also enabled several general conclusions to be drawn. Presented below is only a high-level summary of the findings.

\subsection{Variability of measurements in model test}

Based on the repeated test runs with identical wave trains, the wave elevations, tendon tension and surge motion of the platform are found to have limited variability (CV within $2.8 \%$ ). For the impact pressures, the variability is at least a factor of 3 higher, with CV sometimes reaching $70 \%$. This confirms a higher degree of non-linearity of the impact pressure responses even though five repeated runs were done for each sea state condition. It is therefore recommended that a sufficient number of runs should be performed to allow for this variability of the measured pressure.

\subsection{Platform dynamics and tendon tensions due to extreme wave impact}

In all extreme wave events, compliance of the floating platform in the horizontal direction is seen as having a positive effect by reducing the relative horizontal velocity and alleviating the horizontal wave-in-deck impact, compared with a fixed structure. The maximum tension in the up-wave tendons usually occurred when the wave crest reached the deck leading edge and the forward columns. The maximum tension in the down-wave tendons occurred at about the same time and exceeded tension in the up-wave tendons in some cases.

On average, the wave remained in contact with the deck LE over about $13 \%$ of wave period, which is about $2.2 \mathrm{~s}$ at full scale; during this time the up-wave tendon experienced its peak loading. In many cases, the down-wave tendons experienced a 
rapid reduction in tension up to almost zero, which coincided with a relatively large pitch angle in the down-wave direction, pointing to the effect of the hydrodynamic suction force acting under the deck after the initial impact. This finding is supported by the results of experimental studies (Abdussamie et al, 2016; Scharnke et al, 2014; Scharnke and Henning, 2015) on the wave-in-deck impact problems of fixed decks, which determined that that the magnitude of the downward force caused by the inertia of water flowing down can be as large as the upward impact force. The instantaneous reduction in buoyancy of the aft columns subsequent to the deck impact could also be a contributing factor to cause the tendon to become slack. The slack tendon situations lasted for about $3-4 s$ at full scale. Such situations, if encountered at full scale, may result in tendon disconnection and failure of the platform.

Maximum and minimum tensions experienced by the up-wave and downwave tendons appeared to correlate with the steepness of the extreme wave: the maximum tensions increased and the minimum tension in the down-wave tendon reduced as the wave steepness increased. The wave events that produced the maximum and minimum tendon tension generally did not correspond to the largest wave crest or the largest wave steepness; this indicates that selection of the design wave event or wave train, in the same sea state, may require special attention.

Extreme waves with or even without deck exceedance caused ringing response of the platform and possibly springing. The magnitude of ringing tensions following the wave-in-deck impact was found to exceed the initial pretension by $15 \%$. The duration of ringing response could last for about 8.2 wave periods after the deck impact. 


\subsection{Impact pressure on the deck underside}

The overall trend in the maximum impact pressure, as a function of the deck exceedance, is generally consistent with that predicted by Wang (1970) for a fixed horizontal plate, but with a much broader variability. The forward part of the deck is found to experience higher pressures than the aft part, with the exception of the areas near the ends and around the columns, where this trend is reversed. This could be caused by the wave upwelling being larger around the aft columns and/or the effect of platform set-down as the platform offsets. Over all the wave events tested, the maximum impact pressures around the forward and aft columns show a positive correlation with the maximum tensions in the up-wave and down-wave tendons. This may suggest that the magnitude of wave-in-deck slamming pressure was large enough to rapidly increase the tendon tensions.

\section{Acknowledgments}

The authors would like to acknowledge the assistance from Mr Tim Lilienthal, Mr Kirk Meyer and Mr Liam Honeychurch at the AMC towing tank.

\section{Reference}

Abdussamie, N. (2017). Data Set in MATLAB .fig file of "Experimental investigation of wave-in-deck impact events on a TLP model: Wave Event \#1 (WE\#1)". https://www.researchgate.net/publication/317163075_Data_Set_in_MATLAB_fig_file_of_Exp erimental_investigation_of_wave-in-deck_impact_events_on_a_TLP_model.

Abdussamie, N., Amin, W., Ojeda, R., Thomas, G. \& Drobyshevski, Y. (2014). Irregular Wave Generation and Assessment of Static Air Gap of Offshore Structures. Proceedings of the 19th Australasian Fluid Mechanics Conference, Melbourne, Australia. AFMS. 
Abdussamie, N., Ojeda, R., Drobyshevski, Y., Thomas, G. \& Amin, W. (2016a). Experimental Investigation of Extreme Wave Impacts on a Rigid TLP Model in Cyclonic Conditions. Ships and Offshore Structures, 1-18.

Abdussamie, N., Ojeda, R., Thomas, G. \& Amin, W. (2016b). Measurements of Global and Local Effects of Wave Impact on a Fixed Platform Deck. the Proceedings of the Institution of Mechanical Engineers, Part M: Journal of Engineers for the Maritime Environment.

Almeland, I., Gaul, T., Pettersen, D. \& Vogel, H. (1991). SNORRE TLP Configuration and Analysis Technology. Proceedings of Offshore Technology Conference, Houston, USA. Offshore Technology Conference.

Baarholm, R. (2009). Experimental and Theoretical Study of Three-Dimensional Effects on Vertical Wave-in-Deck Forces. Proceedings of the ASME 28th Int. Conf. on Ocean, Offshore and Arctic Eng., Honolulu, Hawaii, USA. ASME.

Baarholm, R., Faltinsen, O. \& Herfjord, K. (2001). Wave Impact on Decks of Floating Platforms. Practical Design of Ships and Other Floating Structures. Proceedings of the Eighth International Symposium on Practical Design of Ships and Other Floating Structures,.

Baarholm, R. \& Faltinsen, O. M. (2004). Wave Impact Underneath Horizontal Decks. Journal of Marine Science and Technology, 9, 1-13.

Baarholm, R. \& Stansberg, C. T. (2005). Extreme Vertical Wave Impact on the Deck of a Gravity-Based Structure (GBS) Platform. Proc., Rogue Waves 2004.

Bhat, S. S. (1994). Wave Slamming on a Horizontal Plate. MSc thesis, University of British Columbia.

CD-Adapco (2012). User Guide - Star-Ccm+ Version 7.04. CD-Adapco. 
Chen, H.-C., Lee, S.-K. \& Seah, A. K. (2008). Overset Grid CFD Applications for Challenging Offshore Hydrodynamic Problems. ABS Technical Paper.

Deng, Y., Yang, J., Zhao, W., Li, X. \& Xiao, L. (2016). Freak wave forces on a vertical cylinder. Coastal Engineering, 114, 9-18.

DNV (2009). Offshore Standard Det Norske Veritas: Structural Design of TLPs (LRFD Method). Høvik, Norway: Det Norske Veritas, DNV.

DNV (2010). Recommended Practice DNV-RP-C205: Environmental Conditions and Environmental Loads. Høvik, Norway: Det Norske Veritas, DNV.

Fluent, A. (2009). Ansys Fluent 12.0 User Guide. ANSYS Inc.

Hennig, J., Scharnke, J., Buchner, B. \& van den Berg, J. (2011). Extreme LoadResponse Mechanisms of a Tension Leg Platform Due to Larger Wave Crests: Some Results of the 'Crest'JIP. Proceedings of the ASME 30th Int. Conf. on Ocean, Offshore and Arctic Eng., Rotterdam, the Netherlands.

Hirdaris, S. E., Bai, W., Dessi, D., Ergin, A., Gu, X., Hermundstad, O. A., Huijsmans, R., lijima, K., Nielsen, U. D., Parunov, J., Fonseca, N., Papanikolaou, A., Argyriadis, K. \& Incecik, A. (2014). Loads for Use in the Design of Ships and Offshore Structures. Ocean engineering, 78, 131-174.

Johannessen, T., Haver, S., Bunnik, T. \& Buchner, B. (2006). Extreme Wave Effects on Deep Water TIps Lessons Learned from the Snorre a Model Tests. Proc. Deep Offshore Technology, 28-30.

Kaiser, M. J., Yu, Y. \& Jablonowski, C. J. (2009). Modeling Lost Production from Destroyed Platforms in the 2004-2005 Gulf of Mexico Hurricane Seasons. Energy, 34, 1156-1171. 
Kaplan, P. (1992). Wave Impact Forces on Offshore Structures: Re-Examination and New Interpretations. Offshore Technology Conference, OTC 6814, Houston, TX.

Kaplan, P., Murray, J. \& Yu, W. (1995). Theoretical Analysis of Wave Impact Forces on Platform Deck Structures. Proceedings of the ASME 14th Int. Conf. on Ocean, Offshore and Arctic Eng., Copenhagen, Denmark, 18-22 June. New York: ASME.

Lee, S.-K., Yu, K. \& Huang, S. C. (2014). CFD Study of Air-Gap and Wave Impact Load on Semisubmersible under Hurricane Conditions. Proceedings of the ASME $33^{\text {rd }}$ Int. Conf. on Ocean, Offshore and Arctic Eng., 2014 San Francisco, CA, USA. ASME.

Naess, A. \& Gaidai, O. (2011). Extreme Value Statistics of Non-Gaussian Random Wave Fields and the Airgap Problem for Offshore Platforms. Proceedings of the 8th International Conference on Structural Dynamics, Leuven, Belgium.

Niedzwecki, J. \& Huston, J. (1992). Wave Interaction with Tension Leg Platforms. Ocean engineering, 19, 21-37.

Ransley, E. (2015). Survivability of Wave Energy Converter and Mooring Coupled System using CFD. PhD thesis, University of Plymouth.

REUTERS. (2016). North Sea Storm Forces Oil Platform Evacuations, Output Shutdown [Online]. Available: http://www.reuters.com/article/us-weathernorthsea-idUSKBNOUE0OR20151231.

Rudman, M. \& Cleary, P. W. (2013). Rogue Wave Impact on a Tension Leg Platform: The Effect of Wave Incidence Angle and Mooring Line Tension. Ocean Engineering, 61, 123-138. 
Scharnke, J. \& Hennig, J. (2015). Vertical Wave Impact Loading on a Fixed Platform Deck. Proceedings of the ASME 34th Int. Conf. on Ocean, Offshore and Arctic Eng., St. John's, Newfoundland, Canada. American Society of Mechanical Engineers.

Scharnke, J., Vestbostad, T., Wilde, J. d. \& Haver, S. K. (2014). Wave-in-Deck Impact Load Measurements on a Fixed Platform Deck. Proceedings of the ASME 33rd Int. Conf. on Ocean, Offshore and Arctic Eng., San Francisco, CA, USA. American Society of Mechanical Engineers.

Sun, J.-W., Sun, Z.-C., Liang, S.-X. \& Zheng, K. (2011). Spectral Analysis of Random Wave Uplift Force on a Horizontal Deck. Journal of Hydrodynamics, Ser. B, 23, 81-88.

Tromans, P. S., Anaturk, A. R. \& Hagemeijer, P. (1991). A new model for the kinematics of large ocean waves-application as a design wave. Proceedings of the 1st International Offshore and Polar Engineering Conference, Edinburgh, The United Kingdom, International Society of Offshore and Polar Engineers.

Wang, H. 1970. Water Wave Pressure on Horizontal Plate. Journal of the Hydraulics Division, 96, 1997-2017.

Westphalen, J. (2011). Extreme Wave Loading on Offshore Wave Energy Devices using CFD. PhD thesis, University of Plymouth.

Wu, G., Jang, H., Kim, J. W., Ma, W., Wu, M-C., O'Sullivan, J. (2014). Benchmark of CFD modeling of TLP free motion in extreme wave event. Proceedings of the ASME 33rd Int. Conf. on Ocean, Offshore and Arctic Eng., San Francisco, CA, USA. American Society of Mechanical Engineers. 


\section{Appendix}

\section{Wave event WE\#1}

Model scale (1:125): $H=231 \mathrm{~mm}, \eta_{\mathrm{c}}=145 \mathrm{~mm}, T_{\mathrm{z}}=1.48 \mathrm{~s}, \lambda=3.39 \mathrm{~m}, S=0.068$
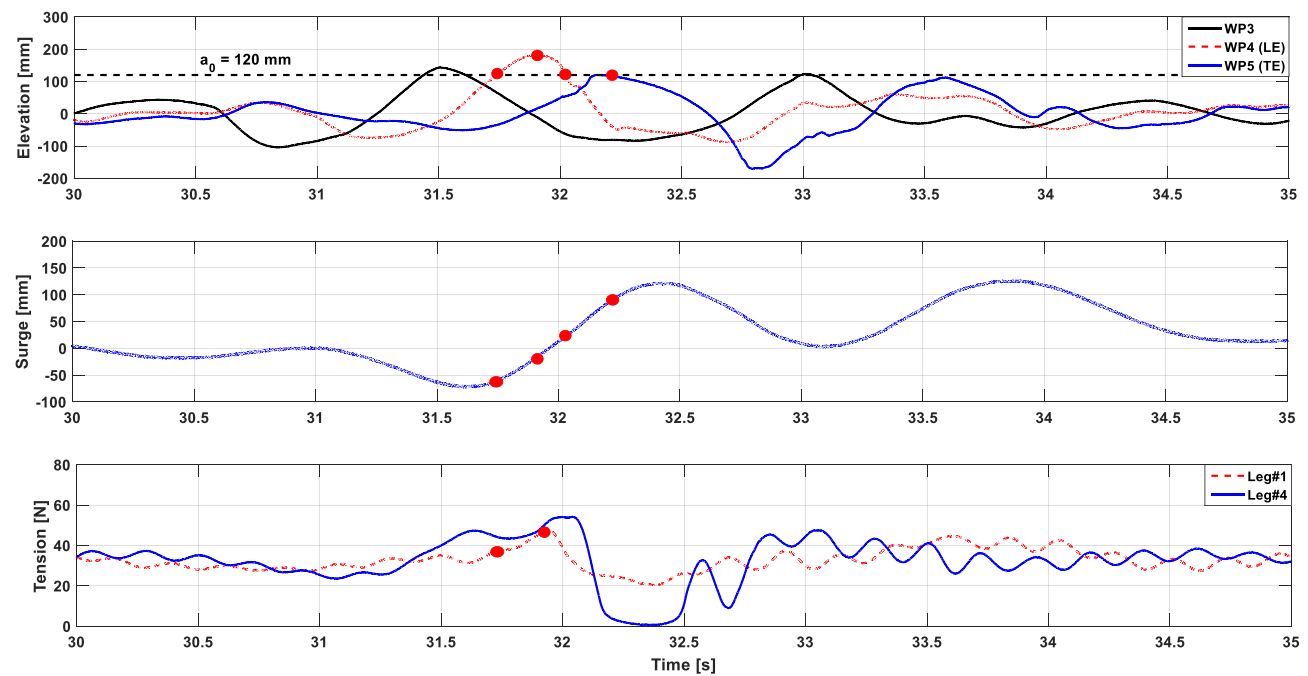

Fig.A 1: Simultaneous measurements: wave elevations (top); surge motion (middle); tendon tension (bottom).

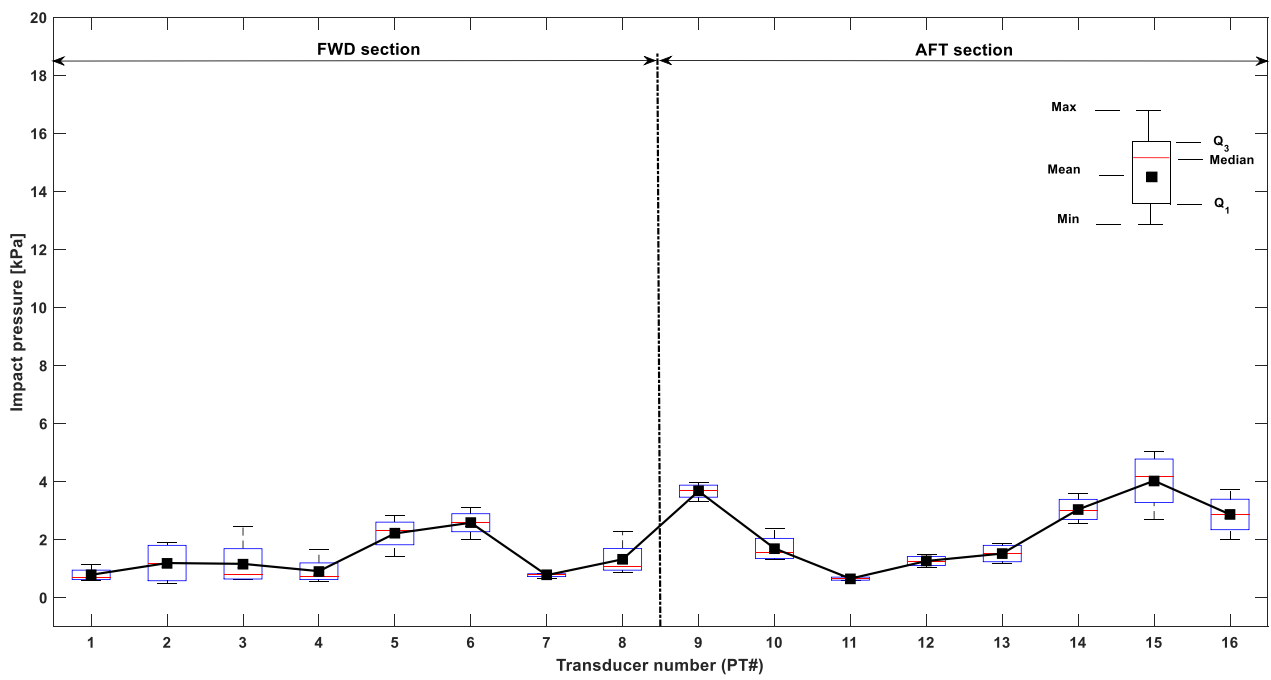

Fig.A 2: Boxplots showing variation in impact pressure at different pressure transducers. 


\section{Wave event WE\#2}

Model scale (1:125): $H=260 \mathrm{~mm}, \eta_{\mathrm{c}}=163 \mathrm{~mm}, T_{\mathrm{z}}=1.37 \mathrm{~s}, \lambda=2.92 \mathrm{~m}, \mathrm{~S}=0.089$
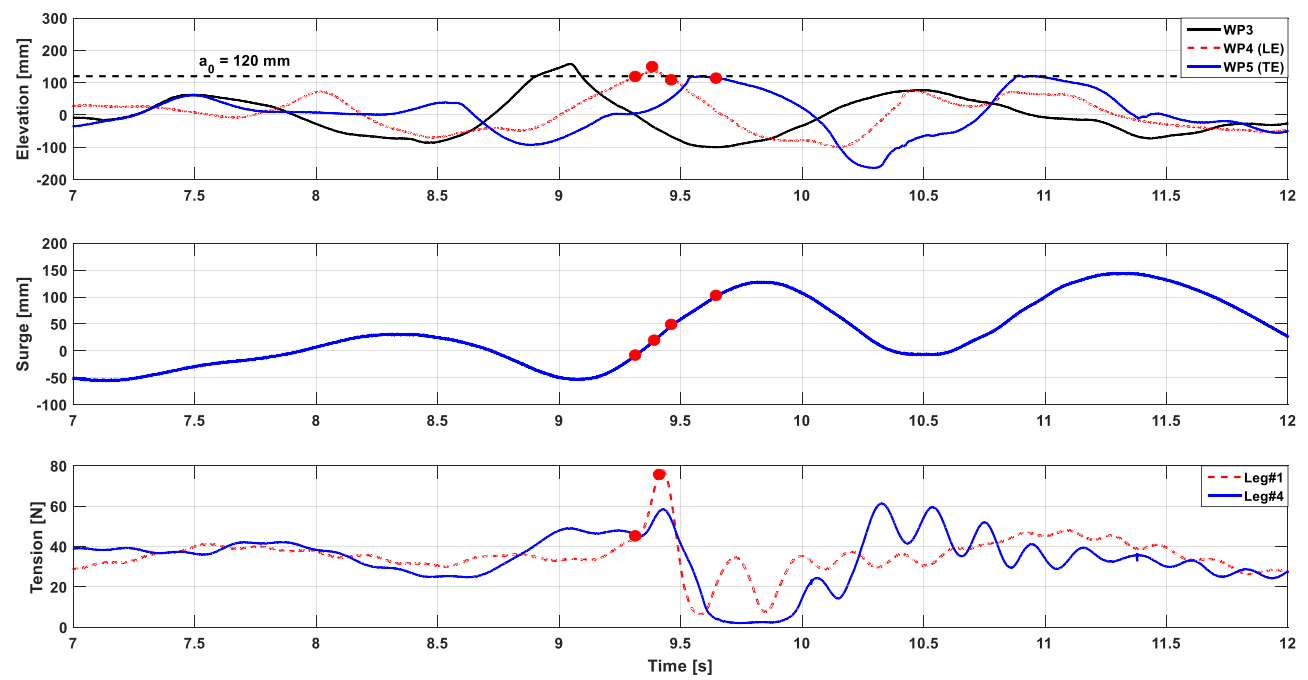

Fig.A 3: Simultaneous measurements: wave elevations (top); surge motion (middle); tendon tension (bottom).

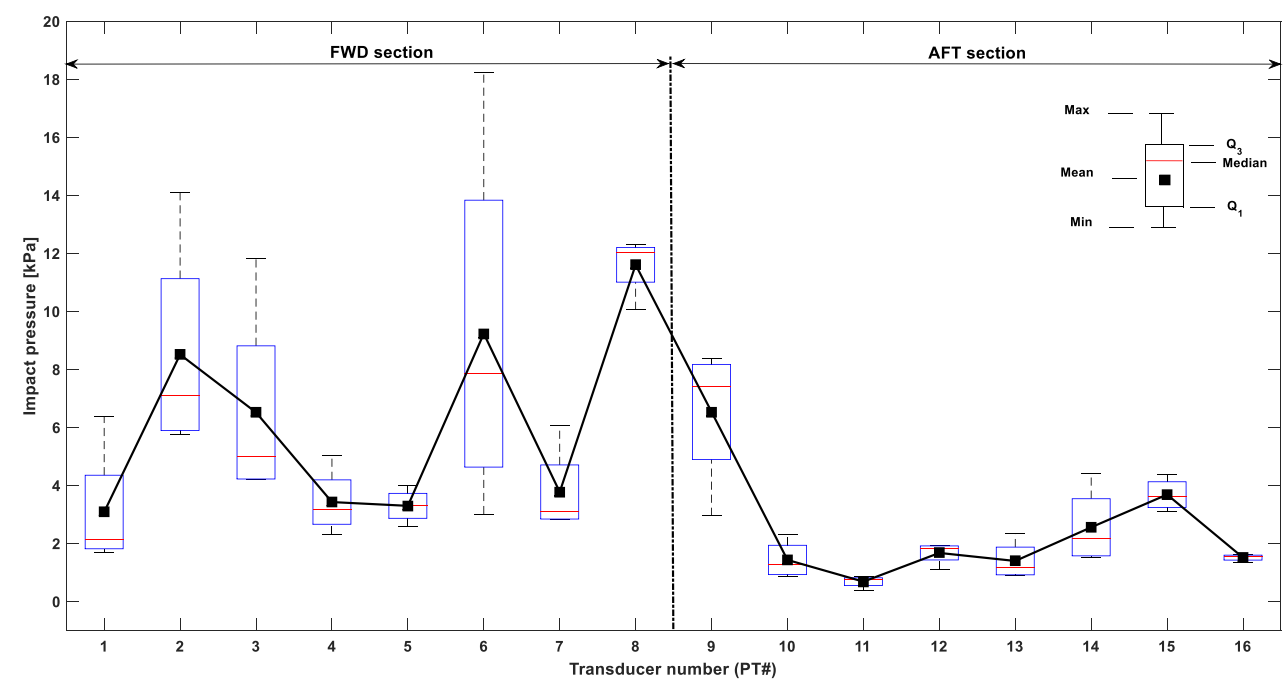

Fig.A 4: Boxplots showing variation in impact pressure at different pressure transducers. 


\section{Wave event WE\#3}

Model scale (1:125): $H=238 \mathrm{~mm}, \eta_{\mathrm{c}}=171 \mathrm{~mm}, T_{\mathrm{z}}=1.65 \mathrm{~s}, \lambda=4.16 \mathrm{~m}, S=0.057$
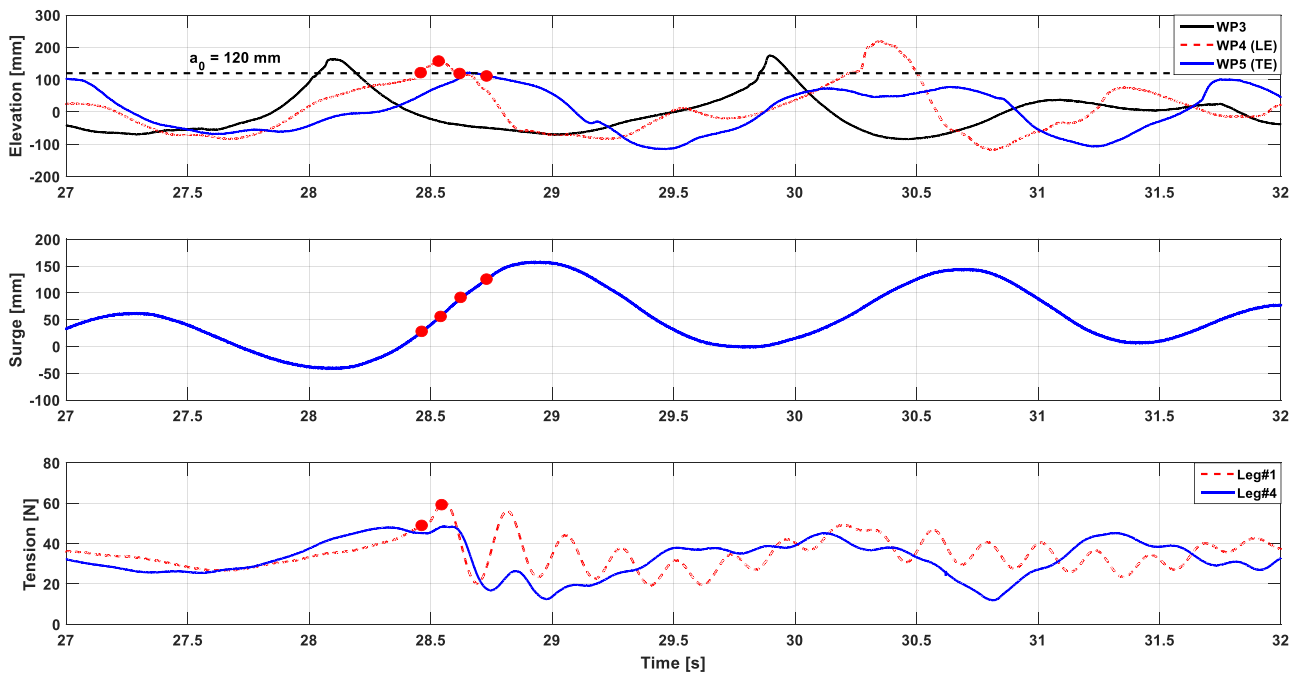

Fig.A 5: Simultaneous measurements: wave elevations (top); surge motion (middle); tendon tension (bottom).

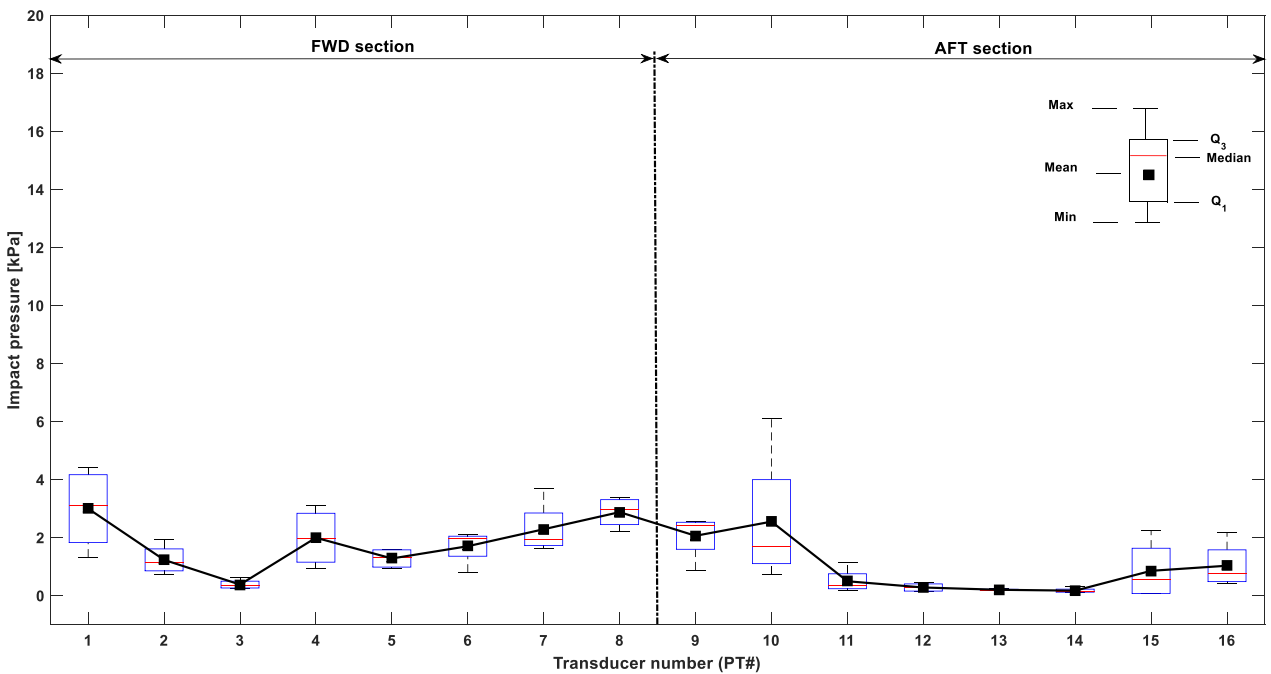

Fig.A 6: Boxplots showing variation in impact pressure at different pressure transducers. 


\section{Wave event WE\#4}

Model scale (1:125): $H=227 \mathrm{~mm}, \eta_{\mathrm{c}}=137 \mathrm{~mm}, T_{\mathrm{z}}=1.35 \mathrm{~s}, \lambda=2.84 \mathrm{~m}, S=0.08$
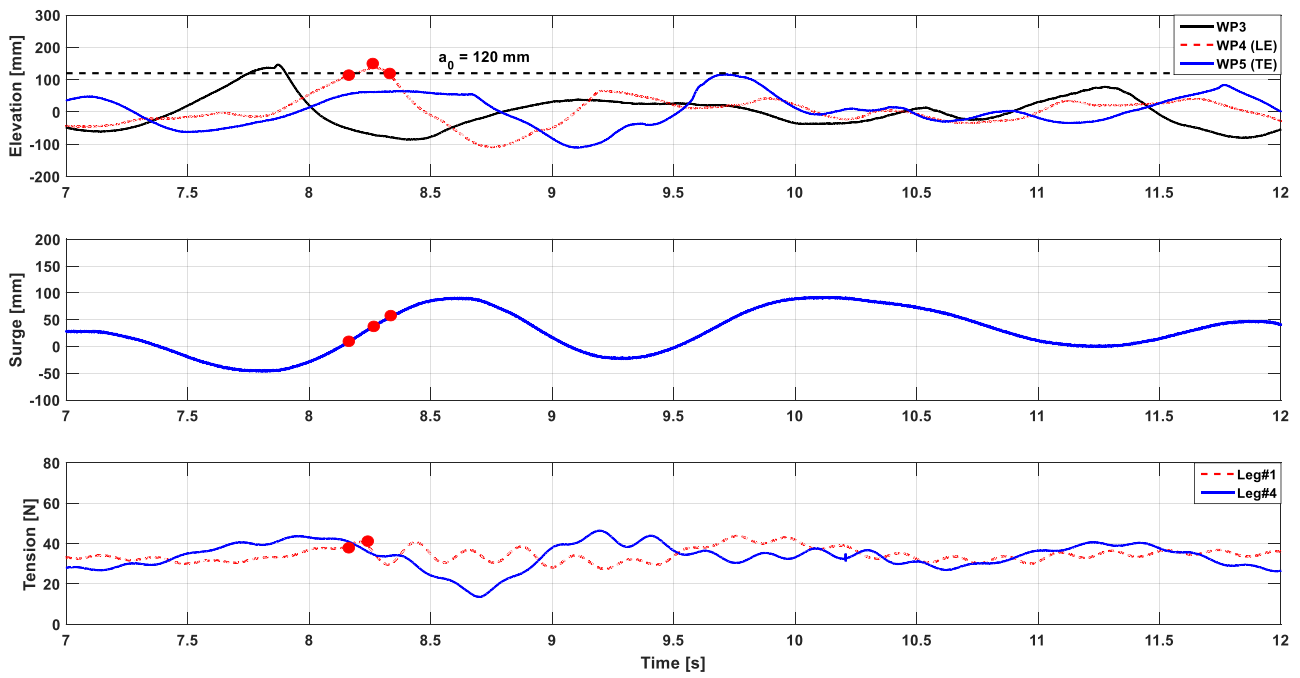

Fig.A 7: Simultaneous measurements: wave elevations (top); surge motion (middle); tendon tension (bottom).

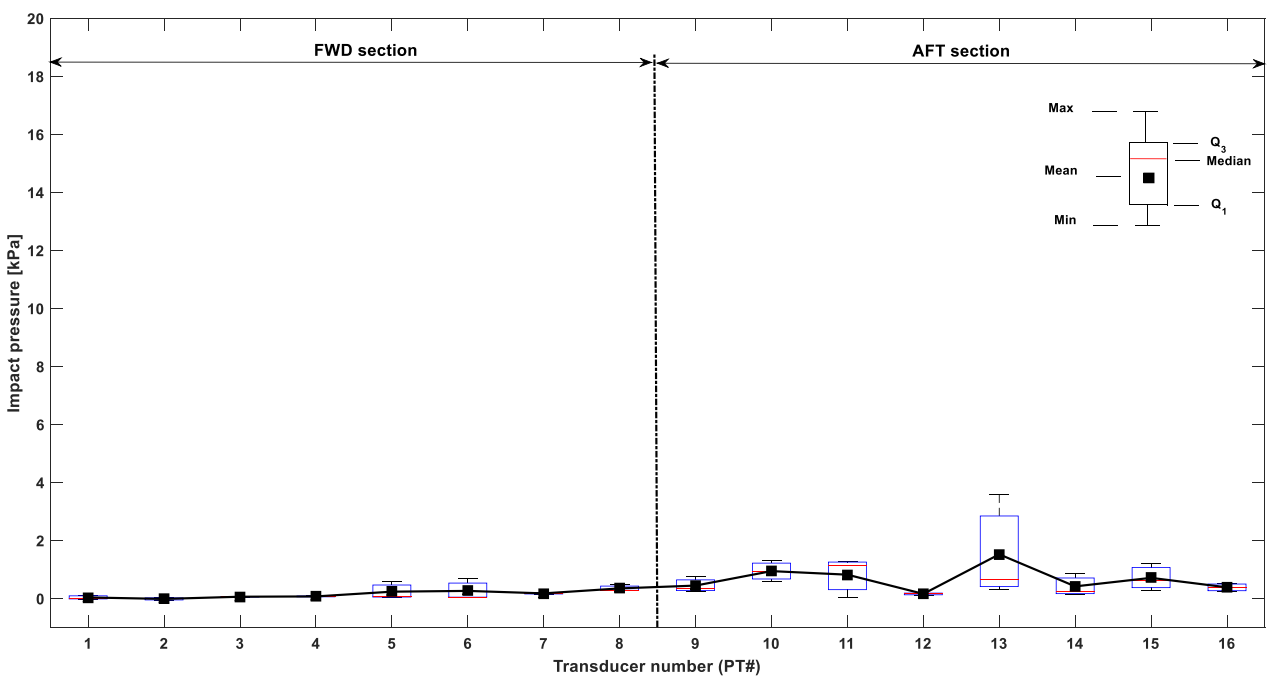

Fig.A 8: Boxplots showing variation in impact pressure at different pressure transducers. 


\section{Wave event WE\#5}

Model scale (1:125): $H=186 \mathrm{~mm}, \eta_{\mathrm{c}}=156 \mathrm{~mm}, T_{z}=1.76 \mathrm{~s}, \lambda=4.67 \mathrm{~m}, S=0.04$
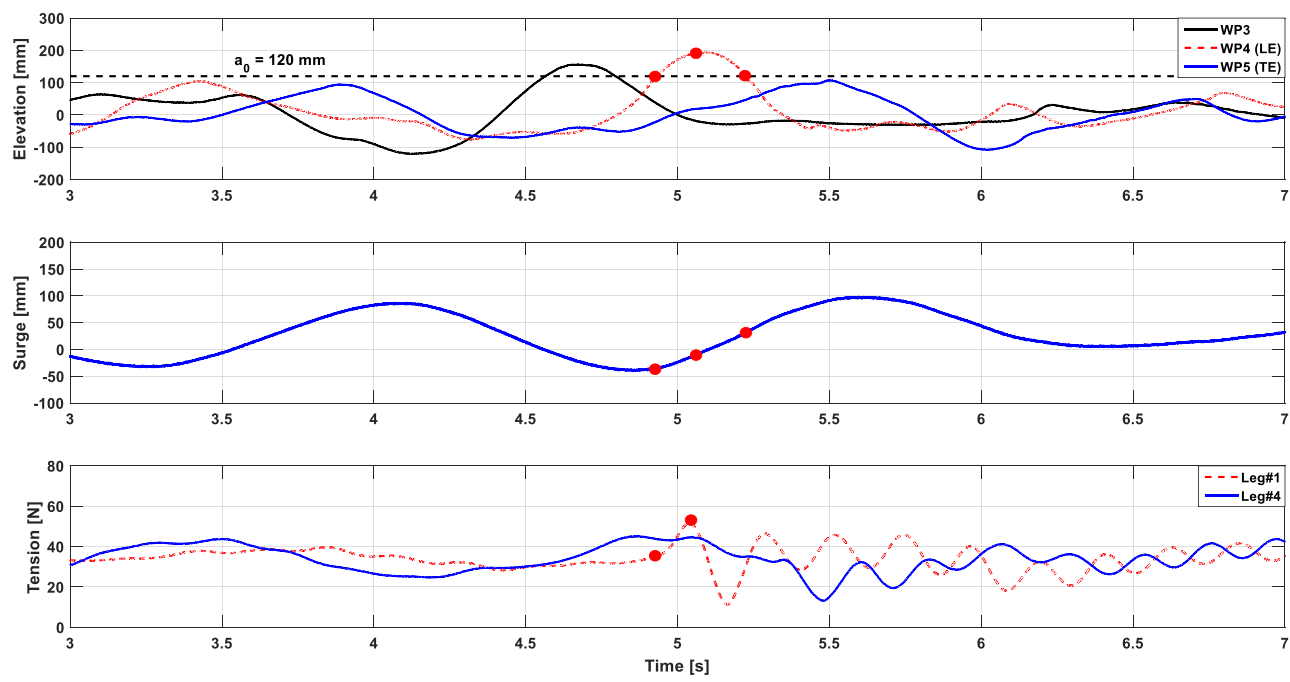

Fig.A 9: Simultaneous measurements: wave elevations (top); surge motion (middle); tendon tension (bottom).

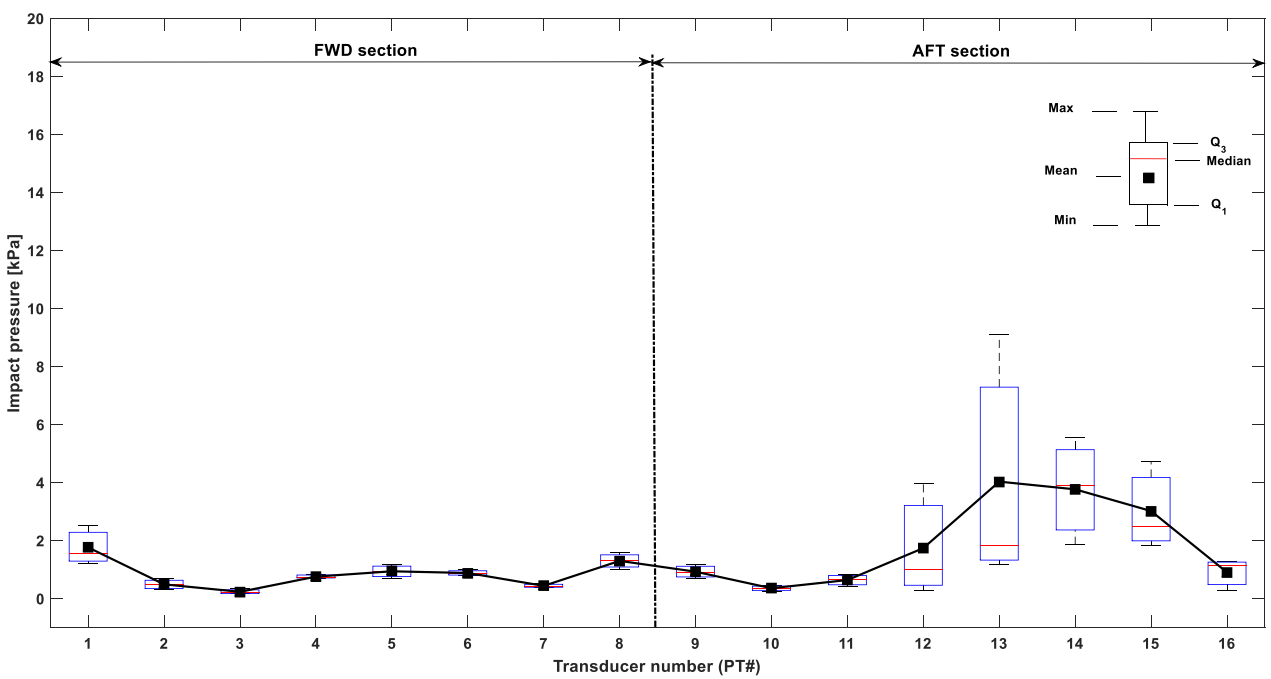

Fig.A 10: Boxplots showing variation in impact pressure at different pressure transducers. 


\section{Wave event WE\#6}

Model scale (1:125): $H=168 \mathrm{~mm}, \eta_{\mathrm{c}}=126 \mathrm{~mm}, T_{\mathrm{z}}=1.73 \mathrm{~s}, \lambda=4.53 \mathrm{~m}, S=0.037$
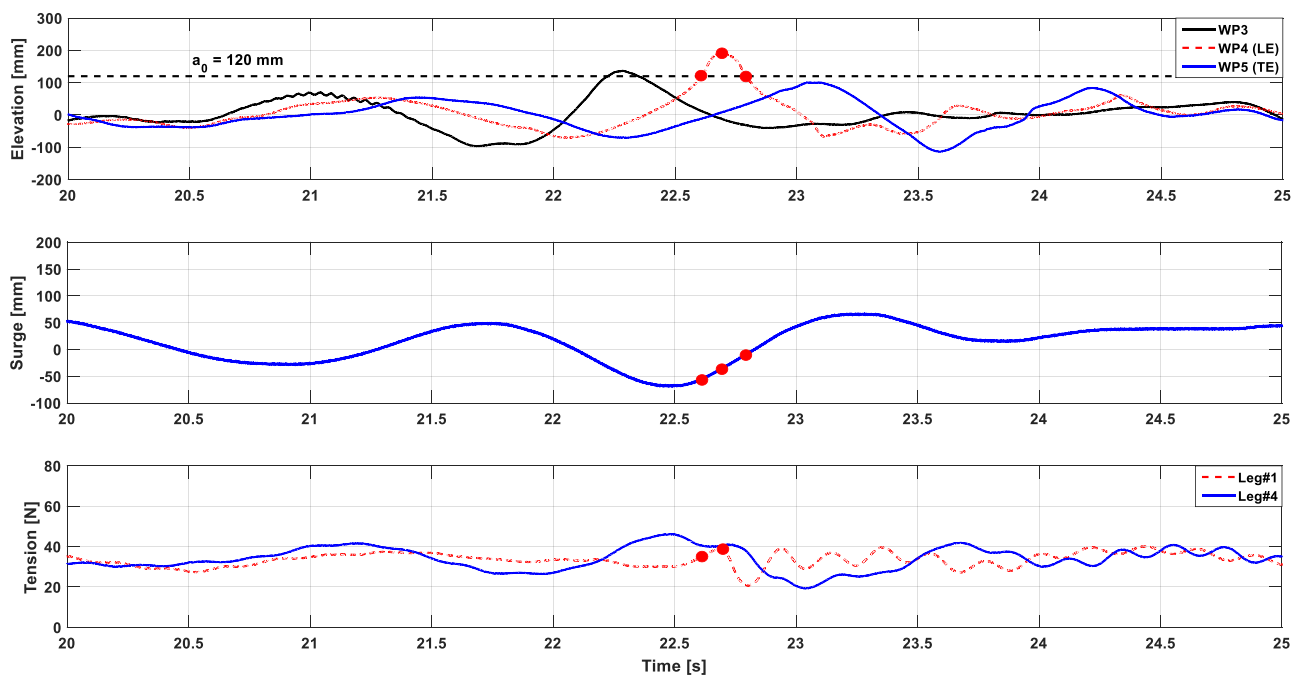

Fig.A 11: Simultaneous measurements: wave elevations (top); surge motion (middle); tendon tension (bottom).

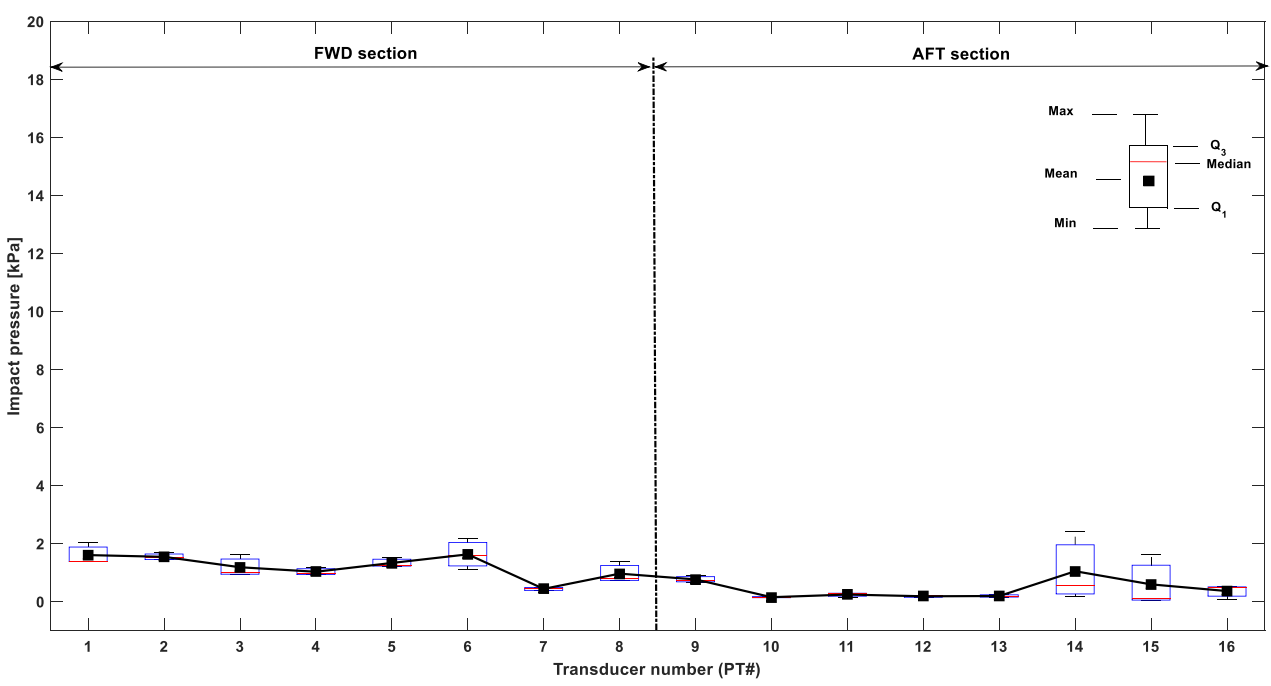

Fig.A 12: Boxplots showing variation in impact pressure at different pressure transducers. 


\section{Wave event WE\#7}

Model scale (1:125): $H=191 \mathrm{~mm}, \eta_{\mathrm{c}}=144 \mathrm{~mm}, T_{\mathrm{z}}=1.44 \mathrm{~s}, \lambda=3.22 \mathrm{~m}, S=0.059$
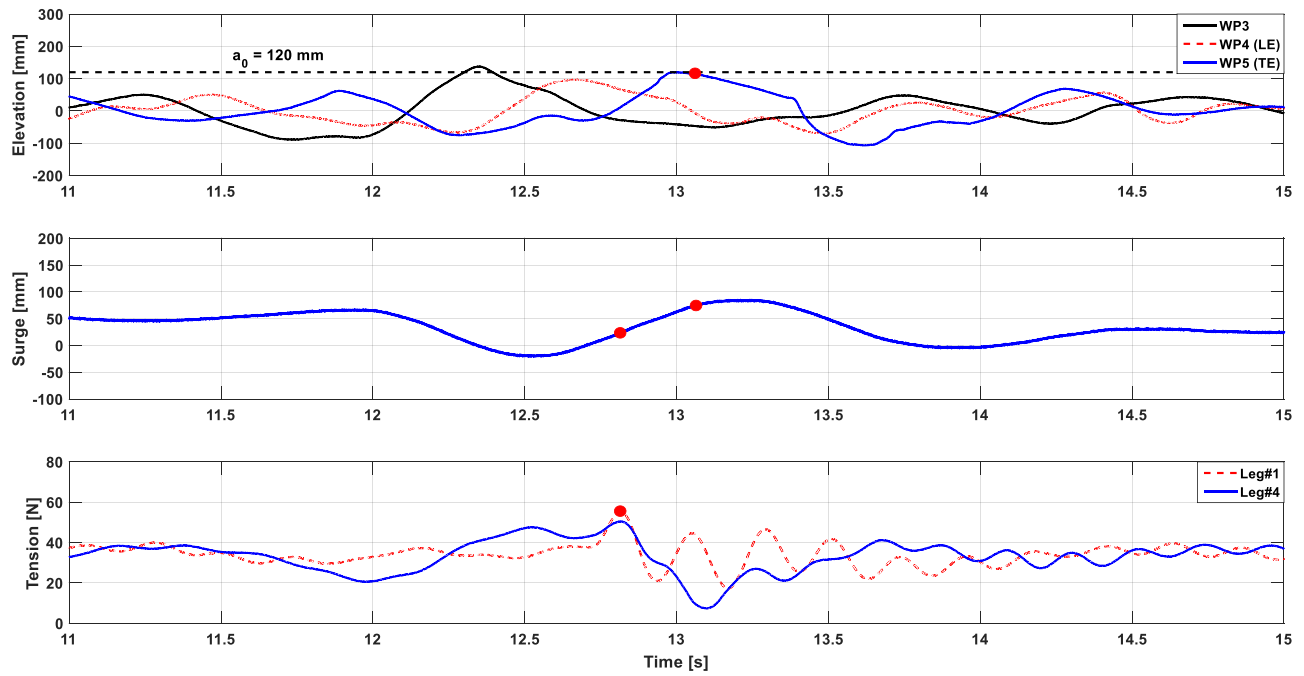

Fig.A 13: Simultaneous measurements: wave elevations (top); surge motion (middle); tendon tension (bottom).

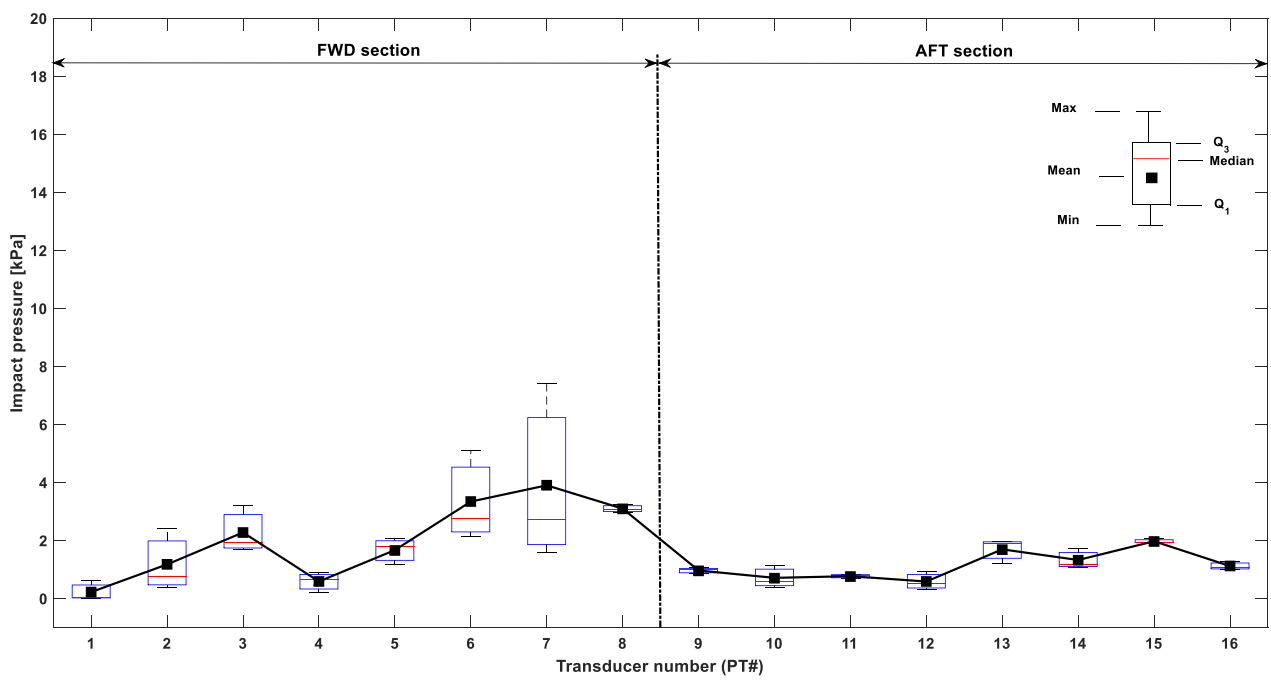

Fig.A 14: Boxplots showing variation in impact pressure at different pressure transducers. 


\section{Wave event WE\#8}

Model scale (1:125): $H=261 \mathrm{~mm}, \eta_{\mathrm{c}}=160 \mathrm{~mm}, T_{\mathrm{z}}=1.46 \mathrm{~s}, \lambda=3.31 \mathrm{~m}, S=0.079$
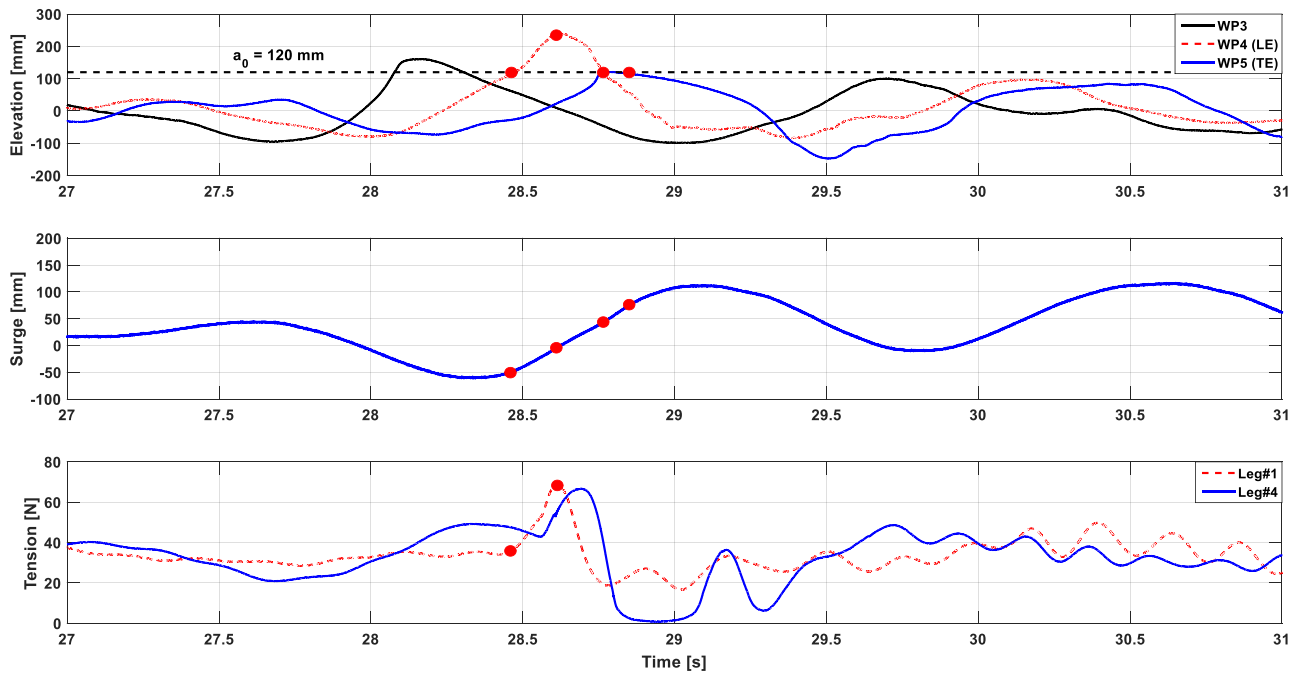

Fig.A 15: Simultaneous measurements: wave elevations (top); surge motion (middle); tendon tension (bottom).

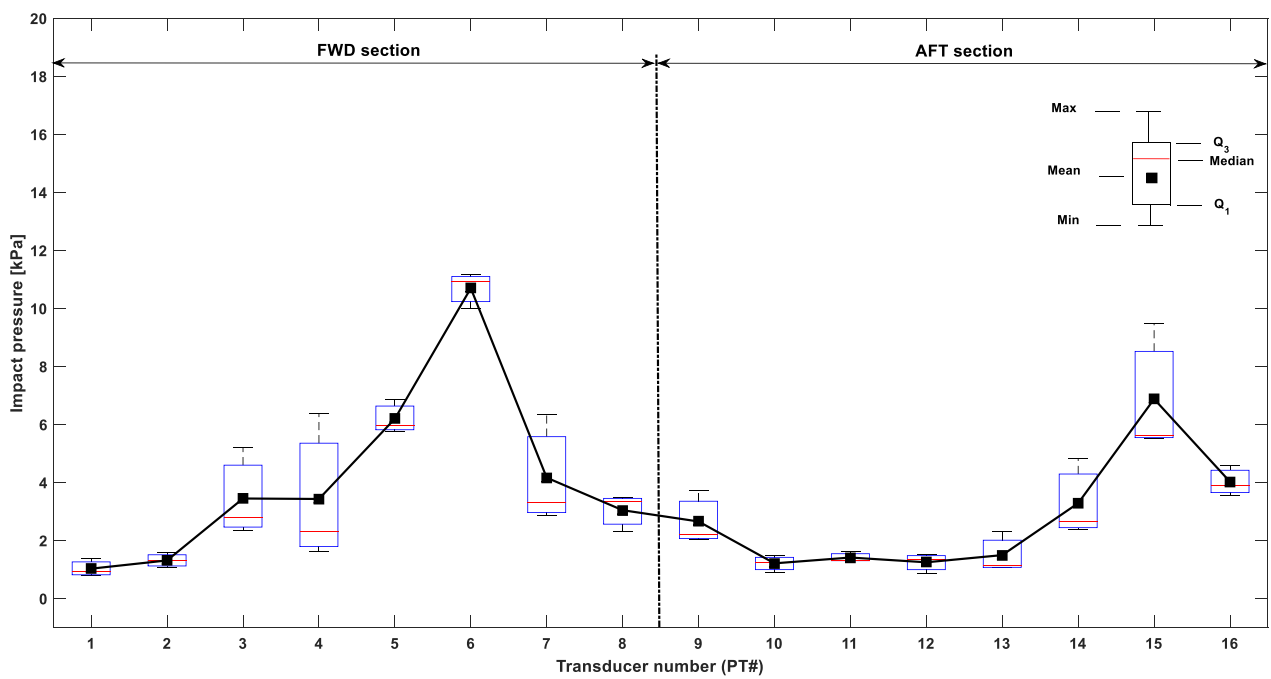

Fig.A 16: Boxplots showing variation in impact pressure at different pressure transducers. 